\title{
Crosslinked polymeric ionic liquids as solid-phase microextraction sorbent coatings for
}

\section{high performance liquid chromatography}

\author{
Honglian Yu, Josias Merib, and Jared L. Anderson*
}

Department of Chemistry, Iowa State University, Ames IA 50011 USA

\section{Abstract}

Neat crosslinked polymeric ionic liquid (PIL) sorbent coatings for solid-phase microextraction (SPME) compatible with high-performance liquid chromatography (HPLC) are reported for the first time. Six structurally different PILs were crosslinked to nitinol supports and applied for the determination of select pharmaceutical drugs, phenolics, and insecticides. Sampling conditions including sample solution $\mathrm{pH}$, extraction time, desorption solvent, desorption time, and desorption solvent volume were optimized using design of experiment (DOE). The developed PIL sorbent coatings were stable when performing extractions under acidic $\mathrm{pH}$ and remained intact in various organic desorption solvents (i.e., methanol, acetonitrile, acetone). The PIL-based sorbent coating polymerized from the IL monomer 1-vinyl-3-(10hydroxydecyl)imidazolium chloride $\left[\mathrm{VC}_{10} \mathrm{OHIM}\right][\mathrm{Cl}]$ and IL crosslinker 1,12-di(3vinylbenzylimidazolium) dodecane dichloride $\left[(\mathrm{VBIM})_{2} \mathrm{C}_{12}\right] 2[\mathrm{Cl}]$ exhibited superior extraction performance compared to the other studied PILs. The extraction efficiency of pharmaceutical drugs and phenolics increased when the film thickness of the PIL-based sorbent coating was increased while many insecticides were largely unaffected. Satisfactory analytical performance was obtained with limits of detection (LODs) ranging from 0.2 to $2 \mu \mathrm{g} \mathrm{L}{ }^{-1}$ for the target analytes. The accuracy of the analytical method was examined by studying the relative recovery of analytes in real water samples, including tap water and lake water, with recoveries varying from $50.2 \%$ to $115.9 \%$ and from $48.8 \%$ to $116.6 \%$, respectively. 


\section{Keywords}

26 Polymeric ionic liquids; Solid-phase microextraction; High-performance liquid chromatography;

27 Pharmaceutical drugs; Phenolics; Pesticides

28

29 *Corresponding Author:

30 Jared L. Anderson

31 Department of Chemistry

32 Iowa State University

331605 Gilman Hall

34 Ames, IA 50011

35 E-mail address: andersoj@iastate.edu

36

37

38

39

40

41

42

43

44

45

46 


\section{Introduction}

Solid-phase microextraction (SPME) has gained tremendous popularity since its

49 introduction in the early 1990s [1]. SPME is a solvent free, cost-effective, and high throughput

50 method that combines sampling and sample preparation into one step. SPME has been widely

51 applied in different areas including environmental [2], food [3], bioanalytical [4], and clinical

52 analysis [5]. This technique is typically performed in either the headspace or direction immersion

53 mode but can be performed using a combination of these modes [6]. The extraction is based on

54 the adsorption and/or partitioning between a sorbent coating and the analytes within the sample

55 matrix. The desorption of analytes from the sorbent coating is performed by either thermal or

56 solvent desorption. SPME is compatible with different separation techniques including gas

57 chromatography (GC) and high performance liquid chromatography (HPLC).

Even though SPME is a mature technique, the continual development of new sorbent

59 coating materials can greatly expand its applicability to a broader range of analytes and matrices.

60 There are a number of commercially-available SPME coatings possessing a wide range of

61 polarity that are currently available on the market. However, the selectivity of these coatings

62 towards target classes of analytes may be inadequate which can severely limit the overall

63 sensitivity of the method. Polymeric ionic liquids (PILs) were first introduced as SPME sorbent

64 coatings for GC and can provide higher selectivity compared to some of the more traditional

65 sorbent coatings [7]. The selectivity of these materials have been progressively improved

66 through the tailoring of the chemical structure within the cation component and by creating

67 unique combinations of cations and anions [8-16].

An area of intense study in SPME involves the extraction of polar analytes from aqueous

69 sample solutions. Due to their high affinity towards the sample matrix, these analytes are 
70 typically extracted in the direct immersion mode. For analytes that are not sufficiently volatile,

71 the development of HPLC-compatible SPME coatings is crucial. The coupling of PIL-based

72 SPME to HPLC requires that the coatings be highly robust when exposed to organic desorption

73 solvents and not slough from the support material. Crosslinked PIL-based sorbent coatings have

74 been recently developed to address this limitation [11]. By crosslinking the PILs, the durability

75 of the sorbent coating can be significantly enhanced, leading to a robust extraction system [13,

76 17-19]. Hybrid materials polymerized from an IL monomer and an organic/inorganic crosslinker

77 have been applied as sorbent coatings for the analysis of various analytes in aqueous samples

78 using SPME-HPLC [19-22]. A PIL-based monolith and its graphene oxide derivative were

79 developed as SPME sorbent coatings for the analysis of polar endocrine disrupting chemicals

80 and phenolic compounds with HPLC [23, 24]. These materials were prepared by

81 azobisisobutyronitrile (AIBN)-initiated polymerization which requires high temperatures,

82 lengthy reaction times (12-24 h), and the use of reaction solvents. Recently, a UV-initiated "on-

83 fiber" polymerization method was introduced to prepare crosslinked PIL-based SPME sorbent

84 coatings that can be immobilized to nitinol supports [17]. This approach is solvent-free and the

85 ensuing polymerization can be achieved within $30 \mathrm{~min}$ to $2 \mathrm{~h}$ through photo-polymerization.

86 Compared to the aforementioned sorbent coating fabrication techniques, this method is simple

87 and efficient. Additionally, the use of sorbent coatings based on neat crosslinked PILs can further

88 enhance the selectivity towards target analytes while imparting necessary structural integrity to

89 the polymeric material when subjected to various organic solvents often used in HPLC.

90 For the first time, we report the use and development of HPLC compatible neat

91 crosslinked PIL-based SPME sorbent coatings for the analysis of pharmaceutical drugs,

92 phenolics, and insecticides. Six structurally diverse PIL-based sorbent coatings were 
93 immobilized on nitinol supports and applied as sorbent materials for SPME. Optimization of the

94 extraction/desorption conditions including sample solution $\mathrm{pH}$, extraction time, desorption

95 solvent, desorption time, and desorption solvent volume were carried out by using the design of

96 experiment (DOE). The newly developed sorbent coatings were exploited for the extraction of

97 target analytes under optimal SPME conditions. The selectivity of the PIL-based coatings was

98 investigated and compared with the commercial PDMS/DVB fiber. The effect of coating film

99 thickness on the extraction efficiency was also studied. Furthermore, the established analytical

100 method was validated by performing extractions in tap water and lake water.

101

102 2. Experimental

1032.1 Reagents and materials

104 The reagents acrylonitrile (99\%), 1-chlorohexadecane (95\%), 1, 12-dibromododecane 105 (98\%), 4-vinylbenzyl chloride (90\%), 10-bromodecanoic acid (95\%), 10-chloro-1-decanol 106 (90\%), 1-vinylimidazole ( $\geq 99 \%)$, imidazole ( $\geq 99 \%)$, vinyltrimethoxysilane (VTMS) (98\%), and 107 2-hydroxyl-2-methylpropiophenone (DAROCUR 1173) (>96\%) were purchased from Sigma108 Aldrich (St. Louis, MO, USA). Acetonitrile, acetone, methanol, isopropanol and dimethyl 109 sulfoxide were also purchased from Sigma-Aldrich with purities equal to or higher than $99 \%$.

110 Hydrogen peroxide $(30 \%$, w/w), glacial acetic acid, hydrochloric acid, and sodium hydroxide 111 were purchased from Fisher Scientific (Fair Lawn, NJ, USA). Lithium 112 bis[(trifluoromethyl)sulfonyl]imide was purchased from SynQuest Laboratories (Alachua, FL, 113 USA). Phenacetin ( $\geq 98 \%)$, ketoprofen ( $\geq 98 \%), 17 \alpha$-ethynylestradiol ( $\geq 98 \%$ ), fenoprofen 114 calcium ( $\geq 97 \%$ ), diclofenac sodium ( $\geq 98.5 \%)$, ibuprofen (98\%), 2,4,6-trichlorophenol (98\%), 115 hexaflumuron (99.1\%), phoxim (98.1\%), chlorfenapyr (98.8\%), flufenoxuron (98.1\%), 
116 hexythiazox (99\%), chlorfluazuron (98.9\%), deltamethrin (99.7\%), fenvalerate (99\%), and $\tau$ -

117 fluvalinate (99\%) were purchased from Sigma-Aldrich. The analyte 2-nitrophenol (99\%) was

118 purchased from Acros Organics (Pittsburgh, PA, USA) and 2,4-dinitrophenol was purchased 119 from Eastman Organic Chemicals (Kingsport, TN, USA). Deuterated dimethyl sulfoxide was 120 purchased from Cambridge Isotope Laboratories (Andover, MA, USA). Nitinol wire with a 121 diameter of $128 \mu \mathrm{m}$ was purchased from Nitinol Devices \& Components (Fremont, CA, USA).

122 The chemical structures and select physicochemical properties of the 18 analytes 123 examined in this study are shown in Table 1. Individual stock solutions of the analytes were 124 prepared at a concentration of $5000 \mathrm{mg} \mathrm{L}^{-1}$. Different organic solvents were used as diluents in 125 the preparation of the individual stock solutions due to the solubility of analytes. Methanol was 126 used as a diluent when preparing the individual stock solutions of phenacetin, $17 \alpha-$ 127 ethynylestradiol, fenoprofen, and diclofenac sodium while acetone was used for preparing the 128 stock solutions of hexaflumuron, flufenoxuron, and chlorfluazuron. All other analyte stock 129 solutions were prepared in acetonitrile. Stock solutions containing a mixture of all analytes were 130 prepared at concentrations of $250 \mathrm{mg} \mathrm{L}^{-1}, 200 \mathrm{mg} \mathrm{L}^{-1}, 10 \mathrm{mg} \mathrm{L}^{-1}$, and $1 \mathrm{mg} \mathrm{L}^{-1}$ using acetonitrile 131 as a diluent. The aqueous sample solutions were prepared by spiking an aliquot of the stock 132 solution into the water sample at an adjusted $\mathrm{pH}$ (using hydrochloric acid and sodium 133 hydroxide). The amount of organic solvent was consistently kept at $0.2 \%(\mathrm{v} / \mathrm{v})$ in the sample 134 solution. All aqueous sample solutions, except the real samples, were prepared with deionized 135 water (18.2 $\mathrm{M} \Omega \mathrm{cm})$ acquired from a Milli-Q water purification system (Bedford, MA, USA). 
139 nuclear magnetic resonance (NMR) spectrometer (Billerica, MA, USA). ${ }^{1} \mathrm{H}$ NMR spectra were

140 collected in deuterated dimethyl sulfoxide. UV-initiated polymerization was carried out using a

141 RPR-100 UV reactor purchased from Southern New England Ultraviolet Company (Bradford,

142 Connecticut). Sixteen lamps producing the same wavelength were applied for the polymerization

143 reaction. A wavelength of $360 \mathrm{~nm}$ was used for the polymerization of the $\mathrm{NTf}_{2}^{-}$based IL

144 monomers and $254 \mathrm{~nm}$ was used for the polymerization of IL monomers containing halide

145 anions. The film thickness of PIL sorbent coatings was examined using a JEOL JSM-6060 LV

146 low vacuum scanning electron microscope (SEM). A representative SEM image of a sorbent

147 coating is shown in Fig. S1.

148 Chromatographic analysis was performed on a Shimadzu LC-20A HPLC (Tokyo, Japan)

149 equipped with a Rheodyne manual injector, two LC-20AT pumps, a DGU-20A 3 degasser, and a

150 SPD-20 UV/Vis detector. The separation of all analytes was carried out using a Restek Ultra C18

151 column $(250 \times 4.6 \mathrm{~mm}$ I.D. $)$ with a particle size of $5.0 \mu \mathrm{m}$ (State College, PA, USA). A gradient

152 separation method was applied starting with $60 \%$ of mobile phase A $(0.05 \%$ acetic acid in water $)$

153 and $40 \%$ of mobile phase B (0.1\% acetic acid in acetonitrile). Mobile phase B was gradually

154 increased from $40 \%$ to $70 \%$ at $2 \mathrm{~mL} \mathrm{~min}^{-1}$ followed by another ramp from $70 \%$ to $85 \%$ at $1 \mathrm{~mL}$

$155 \mathrm{~min}^{-1}$ and an isocratic hold at $85 \%$ for $10 \mathrm{~min}$. The flow rate was maintained at $1 \mathrm{~mL} \mathrm{~min}^{-1}$. A

156 detection wavelength of $220 \mathrm{~nm}$ was used for monitoring 17 -ethynylestradiol, fenoprofen,

157 ibuprofen, deltamethrin, and fenvalerate while all other analytes were monitored at $254 \mathrm{~nm}$.

$159 \quad 2.3$ Synthesis of ionic liquid monomers and crosslinkers 
161 Table 2. The synthesis of IL monomers 1-vinylbenzyl-3-hexadecylimidazolium chloride $162 \quad\left[\mathrm{VBC}_{16} \mathrm{IM}\right][\mathrm{Cl}]$, 1-vinylbenzyl-3-hexadecylimidazolium bis[(trifluoromethyl) sulfonyl]imide 163 [VBC $\left.{ }_{16} \mathrm{IM}\right]\left[\mathrm{NTf}_{2}\right]$, 1-vinyl-3-(2-hydroxyethyl)imidazolium bromide $\left[\mathrm{VC}_{2} \mathrm{OHIM}\right][\mathrm{Br}]$, 1-vinyl-3164 (10-hydroxydecyl)imidazolium chloride $\quad\left[\mathrm{VC}_{10} \mathrm{OHIM}\right][\mathrm{Cl}], \quad$ 1-vinyl-3-(10165 hydroxydecyl)imidazolium bis[(trifluoromethyl) sulfonyl]imide $\quad\left[\mathrm{VC}_{10} \mathrm{OHIM}\right]\left[\mathrm{NTf}_{2}\right]$, and 166 crosslinkers 1,12-di(3-vinylbenzylimidazolium) dodecane dichloride [(VBIM $\left.)_{2} \mathrm{C}_{12}\right] 2[\mathrm{Cl}], 1,12$ 167 di(3-vinylbenzylimidazolium) dodecane dibis[(trifluoromethyl) sulfonyl]imide [(VBIM $)_{2} \mathrm{C}_{12}$ ] $1682\left[\mathrm{NTf}_{2}\right]$ were carried out according to previously published references $[7,28,29]$. The synthesis 169 of IL monomer 1-vinyl-3-(9-carboxynonyl)imidazolium bromide [ $\left.\mathrm{VC}_{9} \mathrm{COOHIM}\right][\mathrm{Br}]$ was 170 performed by mixing $13.3 \mathrm{mmol}$ of 1-vinylimidazole and $20.0 \mathrm{mmol}$ of 10-bromodecanoic acid 171 in acetonitrile. The reaction was carried out at $60{ }^{\circ} \mathrm{C}$ for 3 days. Afterwards, the solvent was 172 removed under vacuum and the product dissolved in $8 \mathrm{~mL}$ of water and washed with ethyl 173 acetate $(4 \mathrm{~mL} \times 6)$ and chloroform $(4 \mathrm{~mL} \times 6)$ to remove unreacted starting materials. The

174 aqueous layer was then collected and dried under vacuum. All final products were characterized 175 by ${ }^{1} \mathrm{H}$ NMR and the spectral data are shown in Figures S1-S8 S2-S9.

1772.4 Fabrication of PIL-based SPME fibers

178 The preparation of PIL-based fibers was performed according to methods from a 179 previously published study [11]. The crosslinked PIL sorbent coatings were produced by "on180 fiber" UV initiated polymerization using derivatized nitinol fibers as supports. Briefly, the nitinol 181 wire was first polished using sand paper and cleaned by acetone and methanol. The metallic wire 182 was then cut into approximately $1.5 \mathrm{~cm}$ segments and placed in a hydrogen peroxide solution 
$183(30 \%, w / w)$. The system was heated at $72{ }^{\circ} \mathrm{C}$ for $2 \mathrm{~h}$ to functionalize the nitinol surface with Ni-

$184 \mathrm{OH}$ groups. Afterwards, the nitinol segments were rinsed with water and methanol followed by

185 heat treatment at $200{ }^{\circ} \mathrm{C}$ for $10 \mathrm{~min}$. The segments were then placed in VTMS and heated at 85

$186{ }^{\circ} \mathrm{C}$ for $2 \mathrm{~h}$ in order to incorporate vinyl functionality onto the support surface. The fibers were

187 ready for coating after being cleaned with methanol and heat treated at $150{ }^{\circ} \mathrm{C}$ for 5 min. A

188 coating mixture consisting of IL monomer, IL crosslinker (50\% by weight with respect to the

189 monomer), and DAROCUR 1173 photoinitiator (3\% by weight with respect to the coating

190 mixture) was evenly applied to the surface of the nitinol fiber. An additional aliquot of deionized

191 water (25\% by weight with respect to the monomer) was added to the coating mixture in order to

192 produce a homogenous coating mixture when preparing Fiber 4. A coating length of $1 \mathrm{~cm}$ was

193 maintained for all fibers examined in this study.

1952.5 Optimization of SPME parameters

196 2.5.1 Optimization of SPME parameters for the PIL-based fibers

197 SPME parameters including sample solution $\mathrm{pH}$, extraction time, desorption solvent, 198 desorption time, and desorption solvent volume were optimized for the PIL-based fibers using 199 Fiber 1 as a model fiber due to its high stability and reproducibility. DOE using the Statsoft 200 Statistica 8.0 program was utilized during the optimization. The desorption solvent was initially 201 optimized due to its low dependence on other parameters. A mixture design was applied using 202 methanol, acetonitrile, and acetone as potential desorption solvents. The optimization was 203 performed by varying the desorption solvent composition. A desorption solvent volume of $50 \mu \mathrm{L}$ 204 was applied for all desorptions and all experiments were performed in duplicate. The optimal 
205 desorption solvent was selected based on the surface response obtained from the average peak 206 areas of all analytes.

207 Prioritization of the other parameters including $\mathrm{pH}$, extraction time, desorption time, and 208 desorption solvent volume were studied using a two level full factorial design. The pH was 209 studied in the range from 2 to 10 and the extraction time was varied from $15 \mathrm{~min}$ to $45 \mathrm{~min}$. The 210 desorption solvent volume was studied from $30 \mu \mathrm{L}$ to $70 \mu \mathrm{L}$ while the desorption time was 211 varied from $5 \mathrm{~min}$ to $25 \mathrm{~min}$. Due to the importance of $\mathrm{pH}$ and extraction time from the two level 212 full factorial design, these parameters were further optimized as individual variables.

213 The optimized conditions were applied for all extractions using the PIL-based fibers.

214 Extractions using the PIL-based fibers were performed in $10 \mathrm{~mL}$ of sample solution at $\mathrm{pH} 1.5$

215 using the direct immersion mode. Prior to exposing the fiber to the matrix, the sample solution 216 was agitated for 2 min to achieve pre-equilibration. Following a 60 min extraction under constant 217 agitation $(450 \mathrm{rpm})$, the fiber was retracted from the aqueous sample and immersed in $30 \mu \mathrm{L}$ of 218 methanol for $15 \mathrm{~min}$. Afterwards, $20 \mu \mathrm{L}$ of the methanolic desorption solvent was withdrawn 219 and subjected to HPLC analysis. Subsequently, the fiber was washed in methanol for 30 min 220 followed by deionized water for $10 \mathrm{~min}$. The washing step was carried out after each extraction221 desorption process in order to minimize carryover. Additionally, the deionized water was 222 acidified to $\mathrm{pH} 3.5$ in the washing of Fiber $\mathbf{4}$ in order to prevent possible ion exchange between 223 the carboxylic acid group in Fiber $\mathbf{4}$ and ionized analytes.

\section{2.5.2 Optimization of SPME parameters for the PDMS/DVB fiber}

226 The extraction/desorption parameters including desorption solvent, $\mathrm{pH}$, and extraction 227 time were studied individually for the PDMS/DVB fiber. The desorption solvent was optimized 
228 using the same method as the PIL-based fibers. A sorption-time profile was generated with the

229 extraction time ranging from 0 to $120 \mathrm{~min}$. The sample solution $\mathrm{pH}$ was varied from 2.5 to 7.5 ,

230 since the lowest suggested working $\mathrm{pH}$ for the PDMS/DVB fiber is 2 . The same desorption time

231 and desorption solvent volume used for the PIL-based fibers was applied for the PDMS/DVB

232 fiber.

233

2342.6 Side-by-side comparison of different PIL coatings, bare supports, and PDMS/DVB fiber

235 The selectivity for target analytes was studied by comparing the extraction efficiency of

236 analytes obtained by the six different PIL sorbent coatings under the optimized

237 extraction/desorption conditions. The effect of PIL sorbent coating film thickness on extraction

238 efficiency was studied by comparing the extraction performance using two fibers polymerized

239 from the $\left[\mathrm{VC}_{10} \mathrm{OHIM}\right][\mathrm{Cl}] \mathrm{IL}$ monomer and the $\left[(\mathrm{VBIM})_{2} \mathrm{C}_{12}\right] 2[\mathrm{Cl}] \mathrm{IL}$ crosslinker with varied

240 film thickness. Two surface derivatized nitinol supports without sorbent coating, namely Fiber a

241 and Fiber b, were also studied under the same extraction/desorption conditions. Fiber a was

242 produced by treating the nitinol fiber with $\mathrm{H}_{2} \mathrm{O}_{2}$ while Fiber $\mathbf{b}$ was produced by treating the fiber

243 with $\mathrm{H}_{2} \mathrm{O}_{2}$ followed by VTMS to functionalize the surface with vinyl moieties. Finally, a

244 PDMS/DVB fiber was also applied for the extraction at the same analyte concentration under the

245 optimized extraction/desorption conditions.

$247 \quad 2.7$ Method validation and recovery using Fiber $3 B$

248 The established analytical method was validated by performing SPME using Fiber 3B in 249 real water samples, including tap water and lake water. Both tap water and lake water were 250 collected locally in Ames, Iowa (USA). The microscopic particles in lake water were removed 
251 by using a polyethersulfone syringe filter $(0.2 \mu \mathrm{m})$. The recovery study was carried out by

252 spiking a known amount of analytes into real water samples with an adjusted $\mathrm{pH}$ of 1.5 . The

253 relative recovery was obtained by comparing the experimental concentration value to the

254 theoretical value.

255

\section{3. Results and discussion}

257 3.1 Structural design of crosslinked PIL-based sorbent coatings

258 Six different PIL-based sorbent coatings based on the combination of various IL 259 monomers and crosslinkers were prepared in this study to explore their selectivity towards target

260 analytes. As shown in Table 1, most analytes contain a number of different substituents including 261 aromatic moieties, carbonyls, secondary amines, hydroxyls, and/or halogens. In order to 262 investigate the interaction between the analytes and sorbent coating, the nature of the PIL sorbent 263 coatings was varied by employing different anions and functional groups appended to the IL 264 cations. Table 2 contains the composition of the six sorbent coatings based on the structural 265 make-up of the IL monomers and crosslinkers. The chloride anion was incorporated in Fiber 2, 3, 266 and 4 in order to enhance the hydrogen bonding basicity of the sorbent coatings compared to 267 Fiber 1 and $\mathbf{6}$ which contain the $\mathrm{NTf}_{2}{ }^{-}$anion. Furthermore, hydroxyl moieties were incorporated 268 in Fiber 3, 5, 6, and carboxylic acid moieties into Fiber 4 in an effort to enhance the hydrogen 269 bonding acidity, which can improve the hydrogen bonding interactions between the PIL and 270 hydrogen bonding basic analytes. The length of alkyl chain substituents in the cation of the 271 monomer was varied in Fiber $\mathbf{3}$ and $\mathbf{5}$ in order to explore the effect of dispersive-type interactions 272 on extraction efficiency. Aromatic moieties were introduced into all of the PIL sorbent coatings 273 to enhance $\pi-\pi$ interactions between the sorbent coating and analytes. Additionally, the 
274 crosslinked structures of the studied PILs can enhance the sorbent coating robustness and

275 resilience when performing analyte desorption using organic solvents.

2773.2 Optimization of extraction/desorption parameters for PIL-based fibers using Fiber 1

278 3.2.1 Mixture Design - optimization of desorption solvent

279 The desorption solvent was optimized using a mixture design consisting of a triangular

280 surface response. Three polar organic solvents including acetonitrile, acetone, and methanol were

281 selected for optimization. The average peak areas of all analytes obtained using the different

282 desorption solvents were plotted to provide insight to their relative desorption strength. A higher

283 average peak area indicates better desorption capability. As shown in Fig. 1A, methanol

284 exhibited slightly better desorption strength compared to acetone while acetonitrile provided the

285 poorest desorption strength. The solvent desorption strength was observed to vary based on the

286 type of analytes. As shown in Fig. S9 S10, methanol was the best desorption solvent for select

287 pharmaceutical drugs and phenolics examined in this study, while acetone exhibited better

288 desorption strength for insecticides. Acetonitrile was found to be the least desirable desorption

289 solvent for all three classes of analytes. Therefore, methanol was chosen as the optimum

290 desorption solvent for subsequent studies.

292 3.2.2 Two level full factorial design - prioritization of the extraction/desorption parameters

293 A two level full factorial design was applied for prioritizing the four 294 extraction/desorption parameters including $\mathrm{pH}$, extraction time, desorption time, and desorption 295 solvent volume. A Pareto chart was generated after plotting the average peak areas of all analytes 296 obtained under different experimental conditions. As shown in Fig. 2, all four parameters 
297 exhibited considerable importance based on the standardized effect estimate ( $\mathrm{p}$ is greater than

298 0.05). The $\mathrm{pH}$ of the sample solution was found to be the most important parameter followed by

299 desorption solvent volume and extraction time. The desorption time was found to be the least

300 important parameter affecting the enrichment of analytes. Additionally, the impact value for the

301 desorption solvent volume is negative indicating that lower desorption solvent volume is more

302 beneficial for the enrichment of analytes. Therefore, a solvent volume of $30 \mu \mathrm{L}$ was chosen for

303 subsequent experiments. The impact value for desorption time was positive suggesting that

304 longer desorption times is more beneficial for the enrichment of analytes. A desorption time of

30515 min was applied for all subsequent studies to form a compromise between the experiment

306 time and enrichment performance.

307

\subsubsection{Optimization of extraction time and sample solution $\mathrm{pH}$}

As two relatively important parameters, the extraction time and sample solution $\mathrm{pH}$ were

310 further studied as individual variables. As shown in Fig. 3A, a sorption-time profile using Fiber 1

311 was generated by varying the extraction time between 0 to $90 \mathrm{~min}$. Most analytes achieved

312 equilibration in approximately $60 \mathrm{~min}$. The peak areas of fenoprofen, ibuprofen, 2,4,6-

313 trichlorophenol, and diclofenac sodium were slightly lower at an extraction time of $90 \mathrm{~min}$

314 compared to $60 \mathrm{~min}$. This may be due to the competition among analytes within the solution.

315 Therefore, an optimal extraction time of 60 min was used when employing the PIL-based fibers

316 for extraction. The precision of the extractions was evaluated at $30 \mathrm{~min}$ and $60 \mathrm{~min}$ and varied

317 from $1.6 \%$ to $18.9 \%$.

318 According to Fig. 2, a negative impact value for $\mathrm{pH}$ was shown in the Pareto chart

319 indicating better enrichment can be achieved at relatively lower $\mathrm{pH}$ values. Therefore, a $\mathrm{pH}$ 
range of 1.5-5.5 was chosen for the optimization experiments. As shown in Fig. 4A, the

321 enrichment of most analytes was enhanced when the $\mathrm{pH}$ of the sample solution was decreased

322 from 5.5 to 1.5. Additionally, the extraction efficiency of phenacetin and $17 \alpha$-ethynylestradiol

323 were similar when the $\mathrm{pH}$ was varied from 1.5 to 4.5 , while the extraction efficiency decreased

324 when the $\mathrm{pH}$ was increased to 5.5. Therefore, a sample solution $\mathrm{pH}$ of 1.5 was applied for the

325 subsequent studies since the best overall extraction efficiency was obtained for most analytes at

326 this $\mathrm{pH}$. A Doehlert design was also performed for simultaneous optimization of sample solution

$327 \mathrm{pH}$ and extraction time. As shown in Fig. S10 S11, the obtained results were consistent with the 328 aforementioned optimization results.

\subsection{Optimization of extraction/desorption parameters for the PDMS/DVB fiber}

Analogous to the PIL-based sorbent coatings, the desorption solvent, extraction time, and

332 sample solution $\mathrm{pH}$ were optimized for the commercial PDMS/DVB coating. Compared to the

333 PIL-based sorbent coating, varying desorption abilities of the studied organic solvents for the

334 analytes were observed when the mixture design was performed for the PDMS/DVB fiber. As

335 shown in Fig. 1B, acetonitrile exhibited the best desorption of the analytes. Interestingly, a

336 mixture of acetonitrile and methanol (50:50, v/v) was the optimal desorption solvent for select

337 pharmaceutical drugs (see Fig. S11 S12). However, acetonitrile was found to be the best

338 desorption solvent for phenolics and insecticides. Additionally, methanol exhibited the poorest

339 desorption strength for phenolics and insecticides. In light of these results, acetonitrile was

340 applied as the desorption solvent of choice for the PDMS/DVB fiber.

341 A sorption-time profile, as shown in Fig. 3B, was generated using the PDMS/DVB fiber

342 at extraction times varying from $0 \mathrm{~min}$ to $120 \mathrm{~min}$. Since most analytes achieved equilibrium at 
$34390 \mathrm{~min}$, an extraction time of $90 \mathrm{~min}$ was selected for further studies. The precision was

344 evaluated at extraction times of $30 \mathrm{~min}$ and $60 \mathrm{~min}$. As shown in Table S1B, the relative standard

345 deviation obtained for all analytes ranged from $0.8 \%$ to $14.7 \%$.

346 The sample solution $\mathrm{pH}$, as shown in Fig. 4B, was studied from 2.5 to 7.5 using the

347 PDMS/DVB fiber. The peak areas of most analytes decreased when the $\mathrm{pH}$ increased from 2.5 to

348 7.5, especially for 2,4-dinitrophenol, ketoprofen, fenoprofen, diclofenac sodium, and ibuprofen.

349 On the other hand, the peak areas of other analytes, such as $17 \alpha$-ethynylestradiol, 2-nitrophenol,

350 2,4,6-trichlorophenol, hexaflumuron, chlorfenapyr, and hexythiazox, were not largely affected

351 when the $\mathrm{pH}$ was varied.

\subsection{Side-by-side comparison of commercial and PIL-based sorbent coatings}

The selectivity of the six different PIL sorbent coatings towards the studied target analytes can be evaluated by comparing their extraction efficiencies, as shown in Fig. 5A and 5B. Fiber 3, possessing a decanol substituent on the imidazolium cation and the chloride counterion, exhibited the best extraction performance for most analytes compared to other PIL-based fibers. Fiber 3, 4, 5, and 6 all contain hydroxyl or carboxylic acid moieties within the monomer

359 cations and exhibited higher selectivity for $17 \alpha$-ethynylestradiol compared to Fiber $\mathbf{1}$ and $\mathbf{2}$,

360 which possess a hexadecyl alkyl chain. This may be due to an enhanced hydrogen bonding

361 interaction between these sorbent coatings and the two hydroxyl groups within the analyte 362 structure. It was also found that Fiber 2 exhibited the lowest extraction efficiency of insecticides 363 compared to the other PIL-based fibers. The film thicknesses of all PIL fibers (shown in Table 2 364 based on SEM images) were comparable, with the exception of Fiber 3B. 
367 same PIL composition but with varying film thicknesses. As shown in Fig. 5A and 5B, the 368 extraction efficiency of pharmaceutical drugs and phenolics increased when using the thicker 369 sorbent coating while the selectivity for the analytes remained the same. Nevertheless, the 370 extraction efficiency of most insecticides remained largely unchanged between the two fibers, 371 with the exception of phoxim and chlorfenapyr. The extraction efficiency of phoxim and 372 chlorfenapyr improved when the film thickness of the sorbent coating was increased. The select 373 pharmaceutical drugs, phenolics, and the two aforementioned insecticides are relatively more 374 polar (Log $P$ varying from 1.65 to 4.88 ) and possess a less bulky structure compared to the rest 375 of the insecticides ( $\log P$ varying from 4.81 to 6.55$)$, which may play a role in the observed 376 extraction behavior.

377 Two surface derivatized supports lacking any PIL sorbent coating, namely, Fiber a and 378 Fiber $\mathbf{b}$, were also studied in the extraction of target analytes. As shown in Figure 5A and 5B, the 379 peak areas of pharmaceutical drugs and phenolics were less than $3 \%$ compared to those obtained 380 for Fiber 3B, except in the case of 2-nitrophenol extracted by Fiber $\mathbf{b}(8.5 \%)$. Even though the 381 bare supports exhibited noticeable extraction of insecticides, they were still considerably lower 382 than most of the PIL-based sorbent coatings. The extraction efficiency of analytes obtained by 383 the PDMS/DVB fiber was comparable to Fiber 3B. The PDMS/DVB fiber exhibited higher 384 extraction efficiency for 2-nitrophenol, 2, 4, 6-trichlorophenol, fenoprofen, ibuprofen, phoxim, 385 chlorfenapyr, and hexythiazox compared to the PIL fiber. However, the extraction efficiency of 38617 a-ethynylestradiol, hexaflumuron, flufenoxuron, chlorfluazuron, deltamethrin, fenvalerate, 387 and $\tau$-fluvalinate were significantly poorer than Fiber 3B. It is also worth noting that extractions 388 using the PDMS/DVB fiber were performed at an extraction time of 90 min which was longer 389 than the PIL fiber. 
3913.5 Analytical performance, method validation, and recovery from real water samples

392 The analytical performance was determined for Fiber 3B by constructing calibration 393 curves and determining limits of detection (LODs) for all analytes as well as the precision of the 394 method. As shown in Table 3, the linear range varied from 1 to $500 \mu \mathrm{g} \mathrm{L}^{-1}$ for most analytes 395 except for ibuprofen and fenvalerate, which were studied from 5 to $500 \mu \mathrm{g} \mathrm{L} \mathrm{L}^{-1}$. Good linearity 396 with correlation coefficients (R) varying from 0.998 to 0.999 was obtained using five 397 concentration levels. The LOD was determined by reducing the analyte concentration until a 3 : 3981 signal : noise ratio was achieved. The LODs of all target analytes using Fiber $\mathbf{3 B}$ varied from 3990.2 to $2 \mu \mathrm{g} \mathrm{L}^{-1}$. The precision of the method was determined at different analyte concentrations,

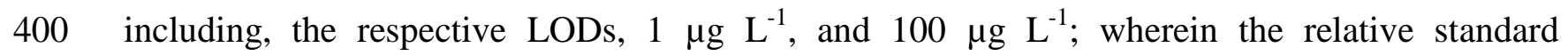
401 deviations (\%RSD) varied from $0.3 \%$ to $19.2 \%$.

402 A recovery study was performed using Fiber 3B in two water samples, namely, tap water 403 and lake water. No detectable signal was observed for any of the analytes studied within both 404 water samples. The recovery study was carried out by performing extractions from the water 405 samples spiked at two different analyte concentration levels. As shown in Table 4, recoveries 406 ranged from $50.2 \%$ to $103.2 \%$ at a spiked concentration of $1.5 \mu \mathrm{g} \mathrm{L}^{-1}$ in tap water, while 407 recoveries ranged from $77.8 \%$ to $115.9 \%$ at $150 \mu \mathrm{g} \mathrm{L}^{-1}$. Acceptable recoveries were also 408 obtained in the lake water matrix; recoveries ranged from $51.2 \%$ to $116.6 \%$ at a spiked 409 concentration of $1.5 \mu \mathrm{g} \mathrm{L}^{-1}$ and from $48.8 \%$ to $111.8 \%$ at $150 \mu \mathrm{g} \mathrm{L}^{-1}$.

\section{4. Conclusions}


413 HPLC for the analysis of pharmaceutical drugs, phenolics, and insecticides. Fiber 3, comprised

414 of a decanol side chain appended to an imidazolium cation and a chloride anion, exhibited the

415 best extraction efficiency for most analytes compared to other coatings. The effect of film

416 thickness on the extraction efficiency was explored, wherein the peak areas of select

417 pharmaceutical drugs and phenolics were increased while the peak areas of most insecticides

418 remained similar when the film thickness increased. LODs at the sub part-per-billion levels were

419 obtained using UV detection. Furthermore, good recoveries were achieved in real water samples,

420 including tap water and lake water. The coatings exhibited long lifetimes; Fiber 1 was used for a

421 total of 155 extraction/desorption cycles. The development of HPLC-compatible PIL sorbent

422 coatings broadens the applicability of these materials towards a larger pool of analytes,

423 particularly non-volatile, polar, and ionizable compounds. The ability to vary the selectivity of

424 the extraction by tailoring the PIL chemical structure as well as enhancing the durability of the

425 materials by crosslinking to super elastic nitinol supports further demonstrates the advantages of

426 these sorbent coatings. On-going studies are aimed at understanding the structure-function

427 relationship of these materials with regard to extraction selectivity as well as examining them in 428 complex environmental and biological matrices.

\section{$430 \quad$ Acknowledgments}

431 The authors acknowledge funding from the Chemical Measurement and Imaging 432 Program at the National Science Foundation (Grant number CHE-1413199). J.M. is grateful to 433 the Brazilian Government Agency Conselho Nacional do desenvolvimento científico e 434 tecnologico for financial support. 
References

437 [1] C.L. Arthur, J. Pawliszyn, Solid phase microextraction with thermal desorption using fused 438 silica optical fibers, Anal. Chem. 62 (1990) 2145-2148.

439 [2] É.A. Souza-Silva, R. Jiang, A. Rodríguez-Lafuente, E. Gionfriddo, J. Pawliszyn, A critical 440 review of the state of the art of solid-phase microextraction of complex matrices I.

441 Environmental analysis, Trends Anal. Chem. 71 (2015) 224-235.

442 [3] É.A. Souza-Silva, E. Gionfriddo, J. Pawliszyn, A critical review of the state of the art of 443 solid-phase microextraction of complex matrices II. Food analysis, Trends Anal. Chem. 71 444 (2015) 236-248.

445 [4] G.A. Gomez-Rios, N. Reyes-Garces, B. Bojko, J. Pawliszyn, Biocompatible-Solid Phase 446 Microextraction (Bio-SPME)-nano-electrospray ionization (nano-ESI): an unexploited tool in 447 bioanalysis, Anal. Chem. doi: 10.1021/acs.analchem.5b03668

448 [5] É.A. Souza-Silva, N. Reyes-Garcés, G.A. Gómez-Ríos, E. Boyaci, B. Bojko, J. Pawliszyn, A 449 critical review of the state of the art of solid-phase microextraction of complex matrices III. 450 Bioanalytical and clinical applications, Trends Anal. Chem. 71 (2015) 249-264.

451 [6] J. Merib, V. Simão, A.N. Dias, E. Carasek, Simultaneous determination of trihalomethanes 452 and organochlorine pesticides in water samples by direct immersion-headspace-solid phase 453 microextraction, J. Chromatogr. A 1321 (2013) 30-37.

454 [7] F. Zhao, Y. Meng, J.L. Anderson, Polymeric ionic liquids as selective coatings for the 455 extraction of esters using solid-phase microextraction, J. Chromatogr. A 1208 (2008) 1-9. 456 [8] Q. Zhao, J.C. Wajert, J.L. Anderson, Polymeric ionic liquids as $\mathrm{CO}_{2}$ selective sorbent 457 coatings for solid-phase microextraction, Anal. Chem. 82 (2010) 707-713. 
458 [9] Y. Meng, J.L. Anderson, Tuning the selectivity of polymeric ionic liquid sorbent coatings for

459 the extraction of polycyclic aromatic hydrocarbons using solid-phase microextraction, J.

460 Chromatogr. A 1217 (2010) 6143-6152.

461 [10] Y. Meng, V. Pino, J.L. Anderson, Role of counteranions in polymeric ionic liquid-based

462 solid-phase microextraction coatings for the selective extraction of polar compounds, Anal.

463 Chim. Acta 687 (2011) 141-149.

464 [11] T.D. Ho, H. Yu, W.T.S. Cole, J.L. Anderson, Ultraviolet photoinitiated on-fiber

465 copolymerization of ionic liquid sorbent coatings for headspace and direct immersion solid-

466 phase microextraction, Anal. Chem. 84 (2012) 9520-9528.

467 [12] J. Feng, M. Sun, L. Xu, J. Li, X. Lu, S. Jiang, Preparation of a polymeric ionic liquid-coated 468 solid-phase microextraction fiber by surface radical chain-transfer polymerization with stainless 469 steel wire as support, J. Chromatogr. A 1218 (2011) 7758-7764.

470 [13] J. Feng, M. Sun, X. Wang, X. Liu, S. Jiang, Ionic liquids-based crosslinked copolymer 471 sorbents for headspace solid-phase microextraction of polar alcohols, J. Chromatogr. A 1245 $472 \quad$ (2012) 32-38.

473 [14] J. Feng, M. Sun, J. Li, X. Liu, S. Jiang, A novel aromatically functional polymeric ionic 474 liquid as sorbent material for solid-phase microextraction, J. Chromatogr. A 1227 (2012) 54-59.

475 [15] M. Cordero-Vaca, M.J. Trujillo-Rodríguez, C. Zhang, V. Pino, J.L. Anderson, A.M.

476 Afonso, Automated direct-immersion solid-phase microextraction using crosslinked polymeric

477 ionic liquid sorbent coatings for the determination of water pollutants by gas chromatography,

478 Anal. Bioanal. Chem. 407 (2015) 4615-4627.

479 [16] H. Yu, T.D. Ho, J.L. Anderson, Ionic liquid and polymeric ionic liquid coatings in solid480 phase microextraction, Trends Anal. Chem. 45 (2013) 219-232. 
482 crosslinked polymeric ionic liquids on nitinol wires produces highly robust sorbent coatings for 483 solid-phase microextraction, Anal. Chim. Acta 843 (2014) 18-26.

484 [18] T.D. Ho, C. Zhang, L.W. Hantao, J.L. Anderson, Ionic liquids in analytical chemistry: 485 fundamentals, advances, and perspectives, Anal. Chem. 86 (2014) 262-285.

486 [19] C. Chen, X. Liang, J. Wang, Y. Zou, H. Hu, Q. Cai, S. Yao, Development of a polymeric 487 ionic liquid coating for direct-immersion solid-phase microextraction using polyhedral 488 oligomeric silsesquioxane as cross-linker, J. Chromatogr. A 1348 (2014) 80-86.

489 [20] K. Liao, M. Mei, H. Li, X. Huang, C. Wu, Multiple monolithic fiber solid-phase 490 microextraction based on a polymeric ionic liquid with high-performance liquid chromatography 491 for the determination of steroid sex hormones in water and urine, J. Sep. Sci. doi:

$492 \quad 10.1002 /$ jssc. 201501156

493 [21] M. Mei, J. Yu, X. Huang, H. Li, L. Lin, D. Yuan, Monitoring of selected estrogen mimics in 494 complicated samples using polymeric ionic liquid-based multiple monolithic fiber solid-phase 495 microextraction combined with high-performance liquid chromatography, J. Chromatogr. A $4961385(2015) 12-19$.

497 [22] M. Mei, X. Huang, J. Yu, D. Yuan, Sensitive monitoring of trace nitrophenols in water 498 samples using multiple monolithic fiber solid phase microextraction and liquid chromatographic 499 analysis, Talanta 134 (2015) 89-97.

500 [23] J. Feng, M. Sun, Y. Bu, C. Luo, Development of a functionalized polymeric ionic liquid 501 monolith for solid-phase microextraction of polar endocrine disrupting chemicals in aqueous 502 samples coupled to high-performance liquid chromatography, Anal. Bioanal. Chem. 407 (2015) $503 \quad 7025-7035$. 
504 [24] M. Sun, Y. Bu, J. Feng, C. Luo, Graphene oxide reinforced polymeric ionic liquid monolith

505 solid-phase microextraction sorbent for high-performance liquid chromatography analysis of

506 phenolic compounds in aqueous environmental samples, J. Sep. Sci. doi:

$507 \quad 10.1002 /$ jssc.201500904

508 [25] C. Bustamante, P. Bustamante, Nonlinear enthalpy-entropy compensation for the solubility

509 of phenacetin in dioxane-water solvent mixtures, J. Pharm. Sci. 85 (1996) 1109-1111.

510 [26] T. Ghafourian, P. Zandasrar, H. Hamishekar, A. Nokhodchi, The effect of penetration

511 enhancers on drug delivery through skin: a QSAR study, J. Control. Release 99 (2004) 113-125.

512 [27] M. Mei, X. Huang, K. Liao, D. Yuan, Sensitive monitoring of benzoylurea insecticides in

513 water and juice samples treated with multiple monolithic fiber solid-phase microextraction and

514 liquid chromatographic analysis, Anal. Chim. Acta 860 (2015) 29-36.

515 [28] Q.Q. Baltazar, J. Chandawalla, K. Sawyer, J.L. Anderson, Interfacial and micellar properties

516 of imidazolium-based monocationic and dicationic ionic liquids, Colloids Surf. A: Physicochem.

517 Eng. Aspects 302 (2007) 150-156.

518 [29] H. Yu, K.D. Clark, J.L. Anderson, Rapid and sensitive analysis of microcystins using ionic

519 liquid-based in situ dispersive liquid-liquid microextraction, J. Chromatogr. A 1406 (2015) 1052018. 
528
Figure 1: Triangular surface responses obtained from the mixture design for optimizing the desorption solvent type using (A) Fiber 1 and (B) PDMS/DVB fiber. Concentration of analytes: $400 \mu \mathrm{g} \mathrm{L}{ }^{-1}$; Extraction time: $30 \mathrm{~min}$; Desorption time: $15 \mathrm{~min}$; Desorption solvent volume: 50 $\mu \mathrm{L}$.

Figure 2: Pareto chart obtained using Fiber 1 for prioritizing the four extraction/desorption parameters $\mathrm{pH}$, extraction time, desorption time, and desorption solvent volume.

Figure 3: Sorption-time profiles obtained using (A) Fiber 1 and (B) PDMS/DVB fiber. Concentration of analytes: $400 \mu \mathrm{g} \mathrm{L}{ }^{-1}$; Desorption time: $15 \mathrm{~min}$. (A). pH: 1.5; Desorption solvent: $30 \mu \mathrm{L}$ of methanol. (B). pH: 2.0; Desorption solvent $30 \mu \mathrm{L}$ of acetonitrile. (ם) Phenacetin; ( $\diamond)$ 2,4-Dinitrophenol; ( $\Delta$ ) 2-Nitrophenol; (x) Ketoprofen; (*) $17 \alpha$-Ethynylestradiol; (-) Fenoprofen calcium; (-) 2,4,6-Trichlorophenol; (o) Diclofenac sodium; (+) Ibuprofen; (ם) Hexaflumuron; ( $\diamond$ Phoxim; ( $\Delta$ ) Chlorfenapyr; ( $)$ Flufenoxuron; (*) Hexythiazox; (₫)

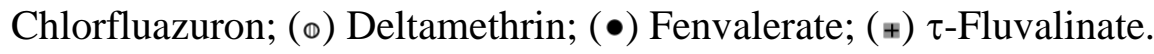

Figure 4: Optimization of sample solution $\mathrm{pH}$ using (A) Fiber 1 and (B) PDMS/DVB fiber. Concentration of analytes: $400 \mu \mathrm{g} \mathrm{L}{ }^{-1}$; Desorption time: $15 \mathrm{~min}$. (A). Extraction time: $60 \mathrm{~min}$; Desorption solvent: $30 \mu \mathrm{L}$ of methanol. (B). Extraction time: $90 \mathrm{~min}$; Desorption solvent

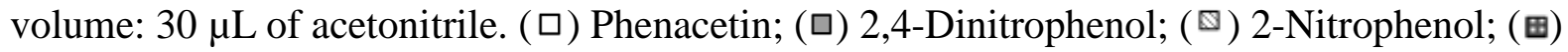

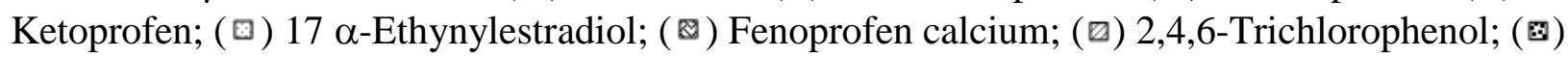

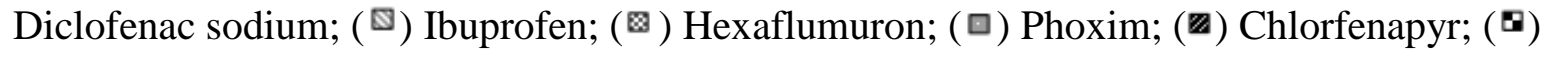

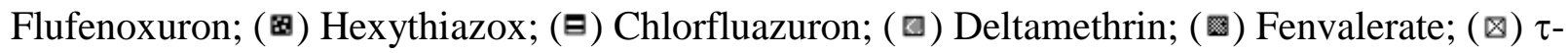
Fluvalinate.

Figure 5: Extraction efficiency comparison of 18 analytes using the various sorbent coatings examined in this study. Concentration of analytes: $200 \mu \mathrm{g} \mathrm{L}^{-1}$; Extraction time: $60 \mathrm{~min}$ (PIL fibers), 90 min (PDMS/DVB); Desorption solvent: methanol (PIL fibers), acetonitrile (PDMS/DVB); pH: 1.5 (PIL fibers), 2 (PDMS/DVB); Desorption time: 15 min; Desorption solvent volume: $30 \mu \mathrm{L}$. (A). (口) Phenacetin; (ㅁ) 2,4-Dinitrophenol; ( $\square$ ) 2-Nitrophenol; (田)

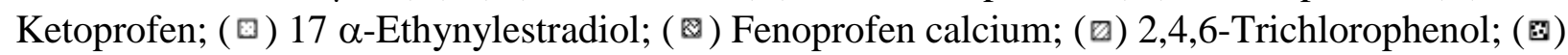

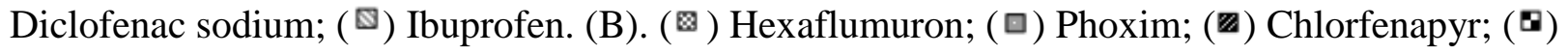

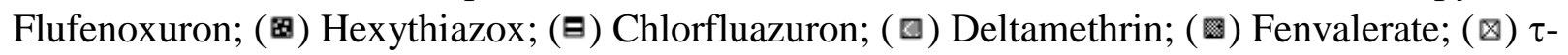
Fluvalinate. 


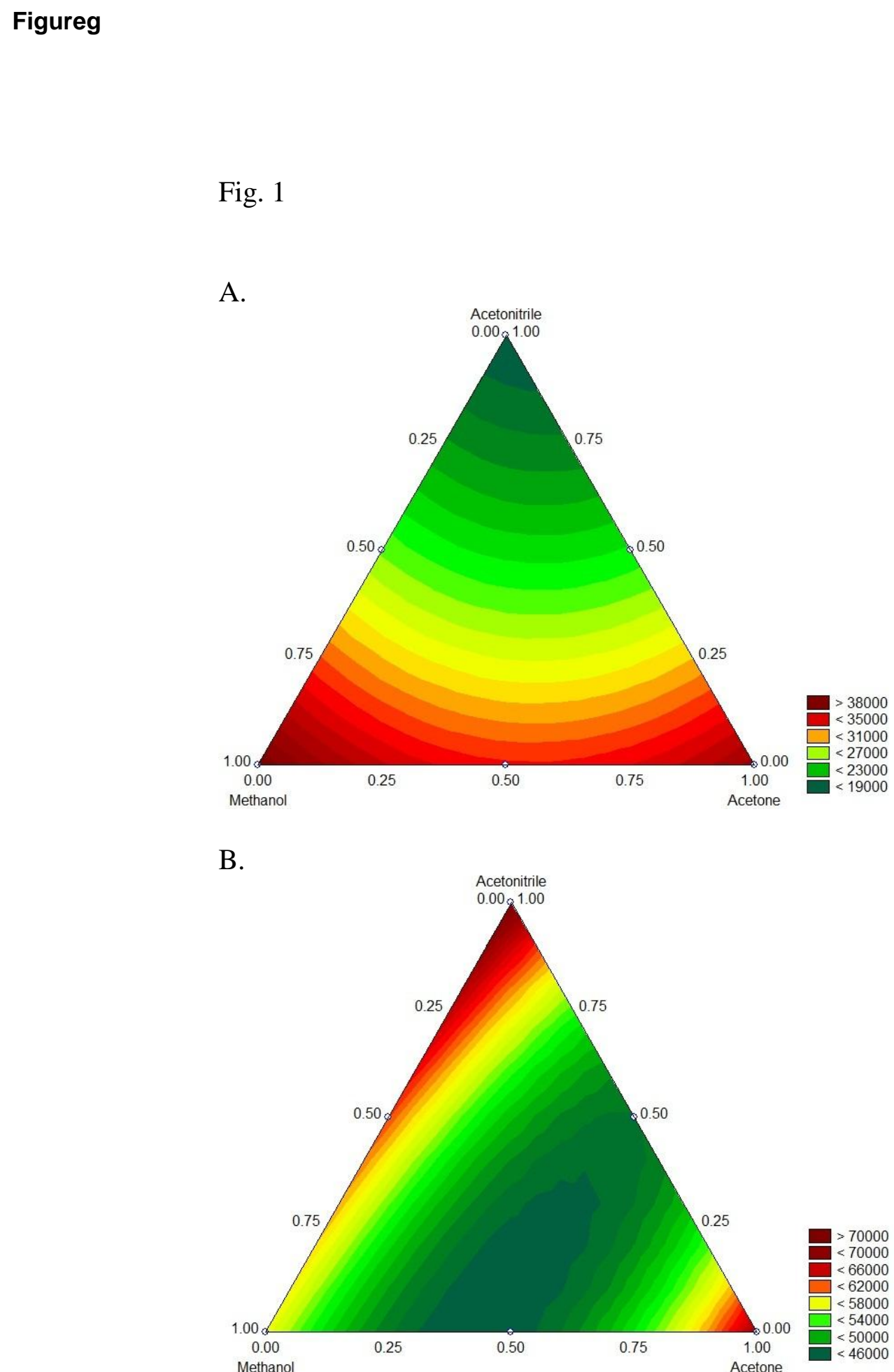

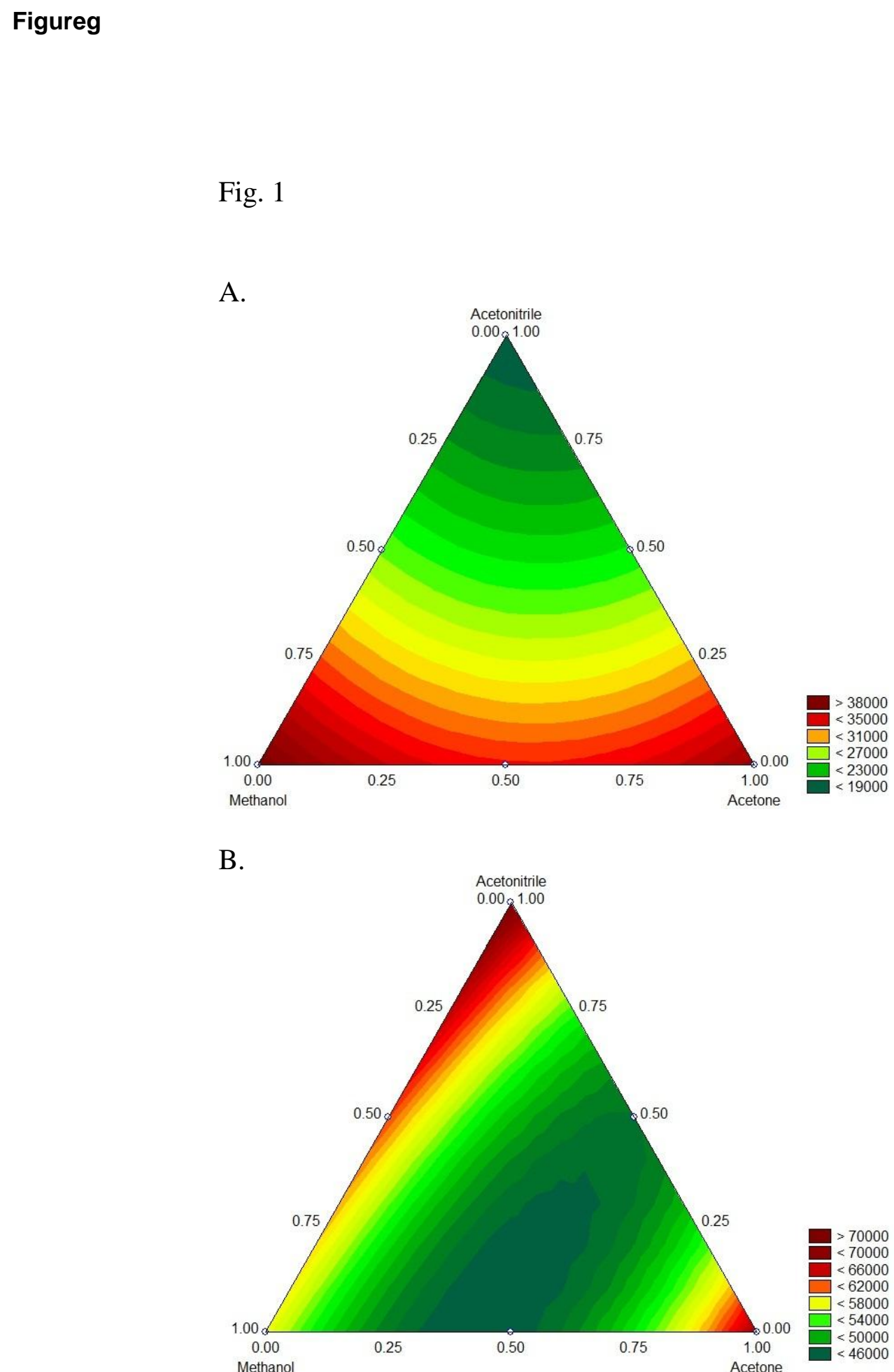

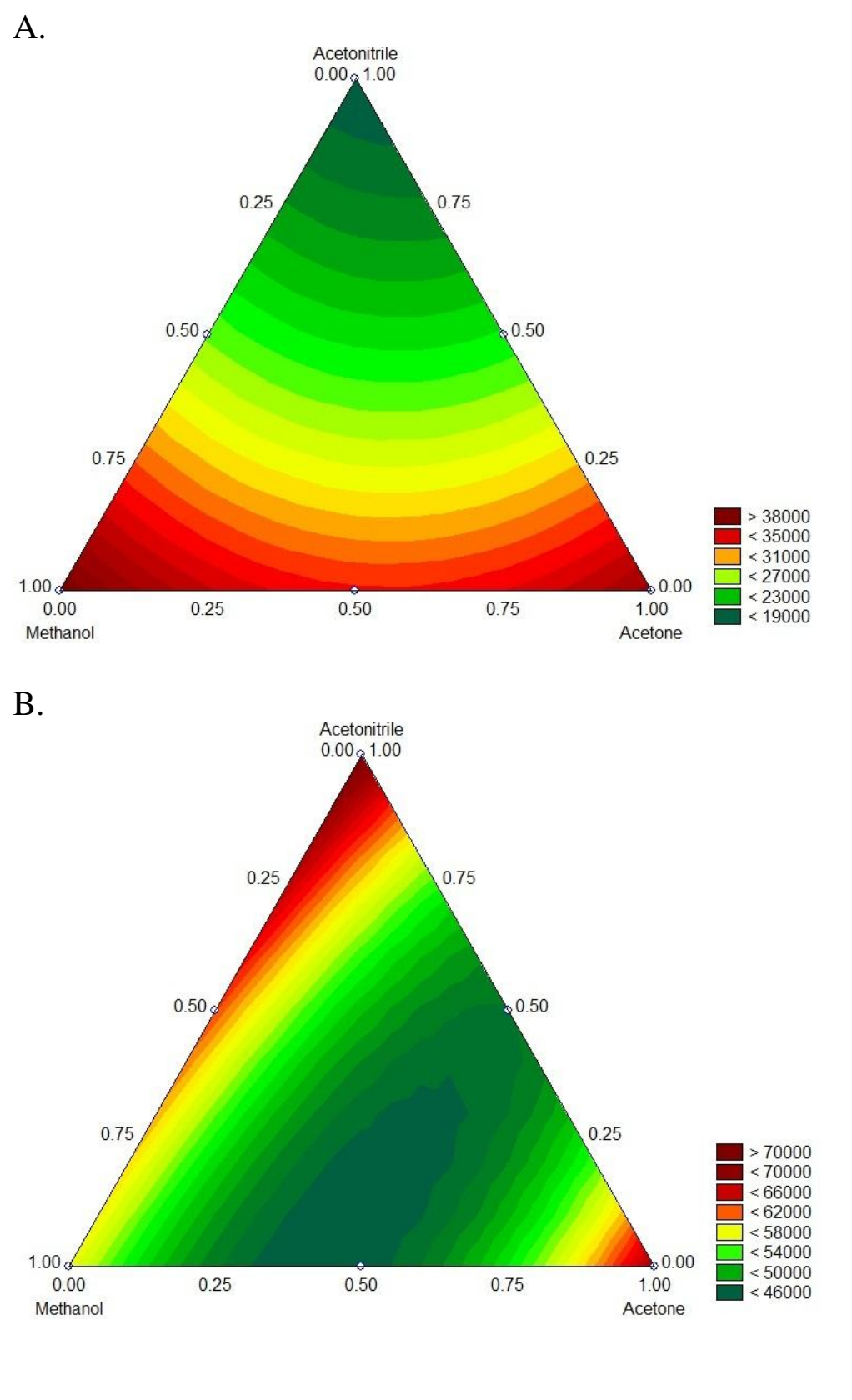

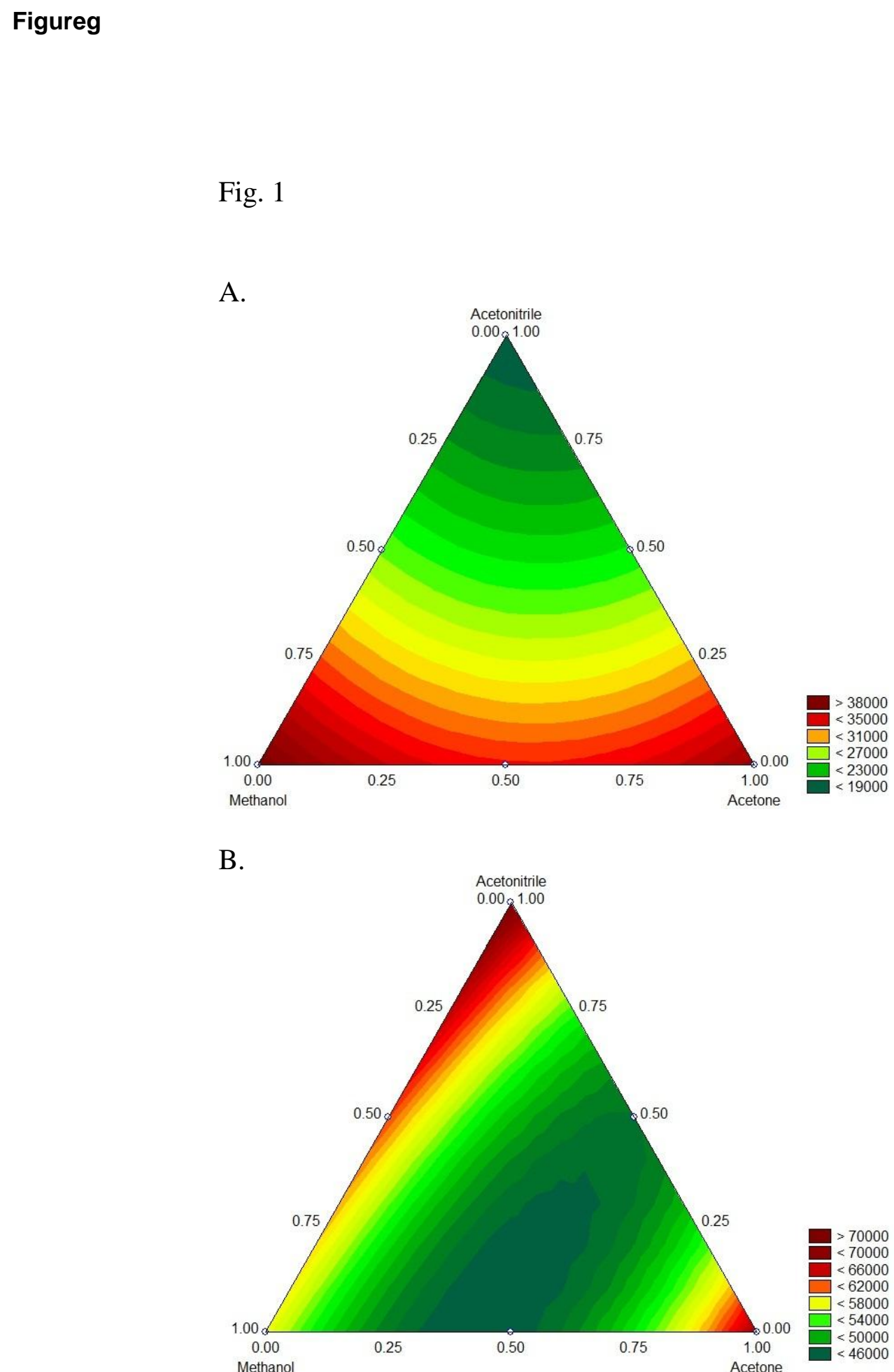
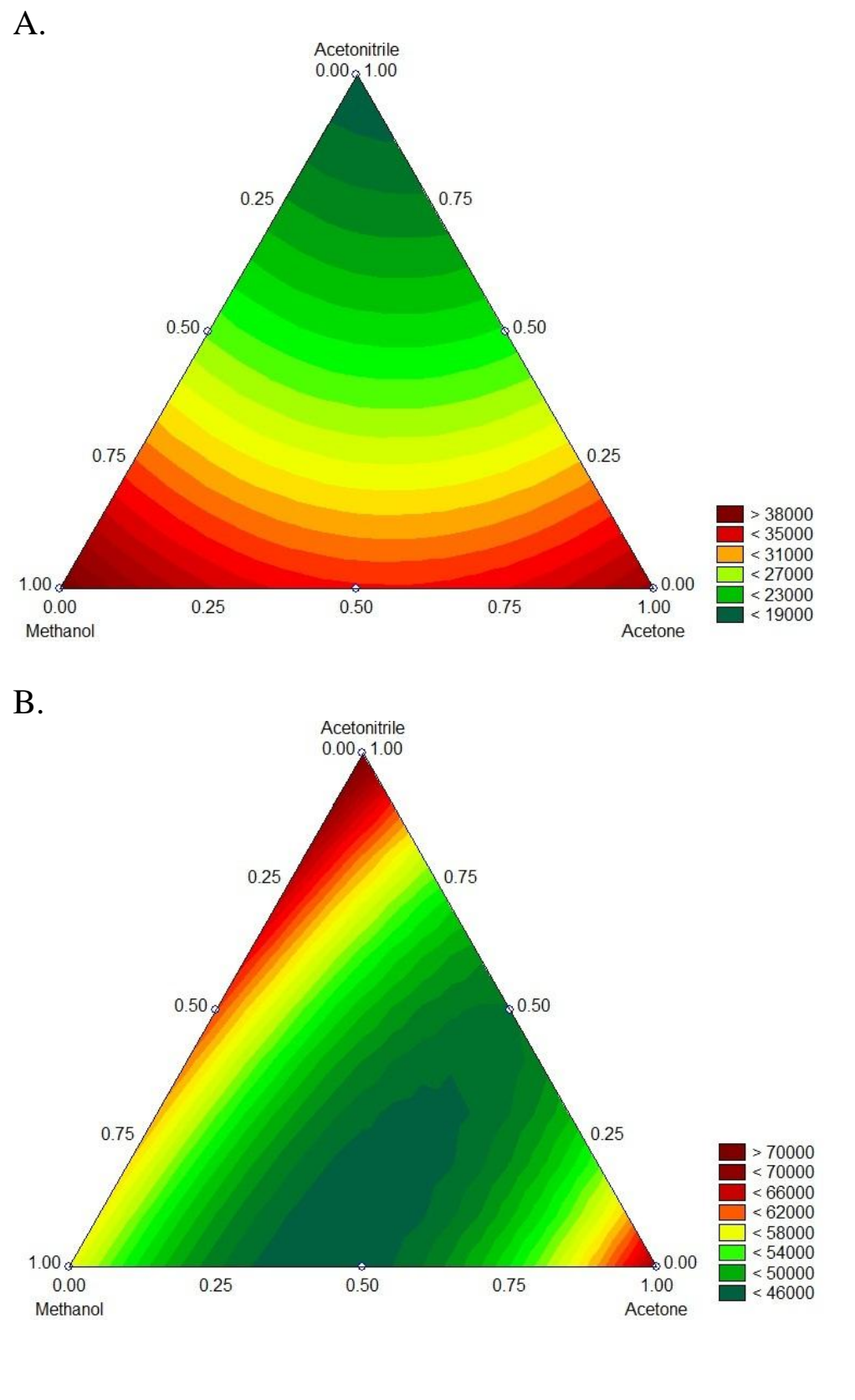

.

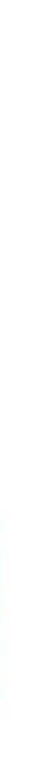

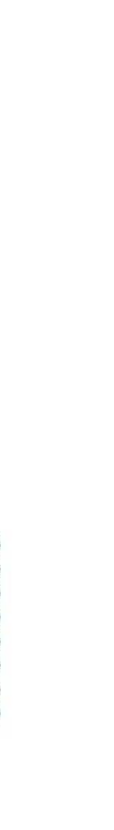


Fig. 2

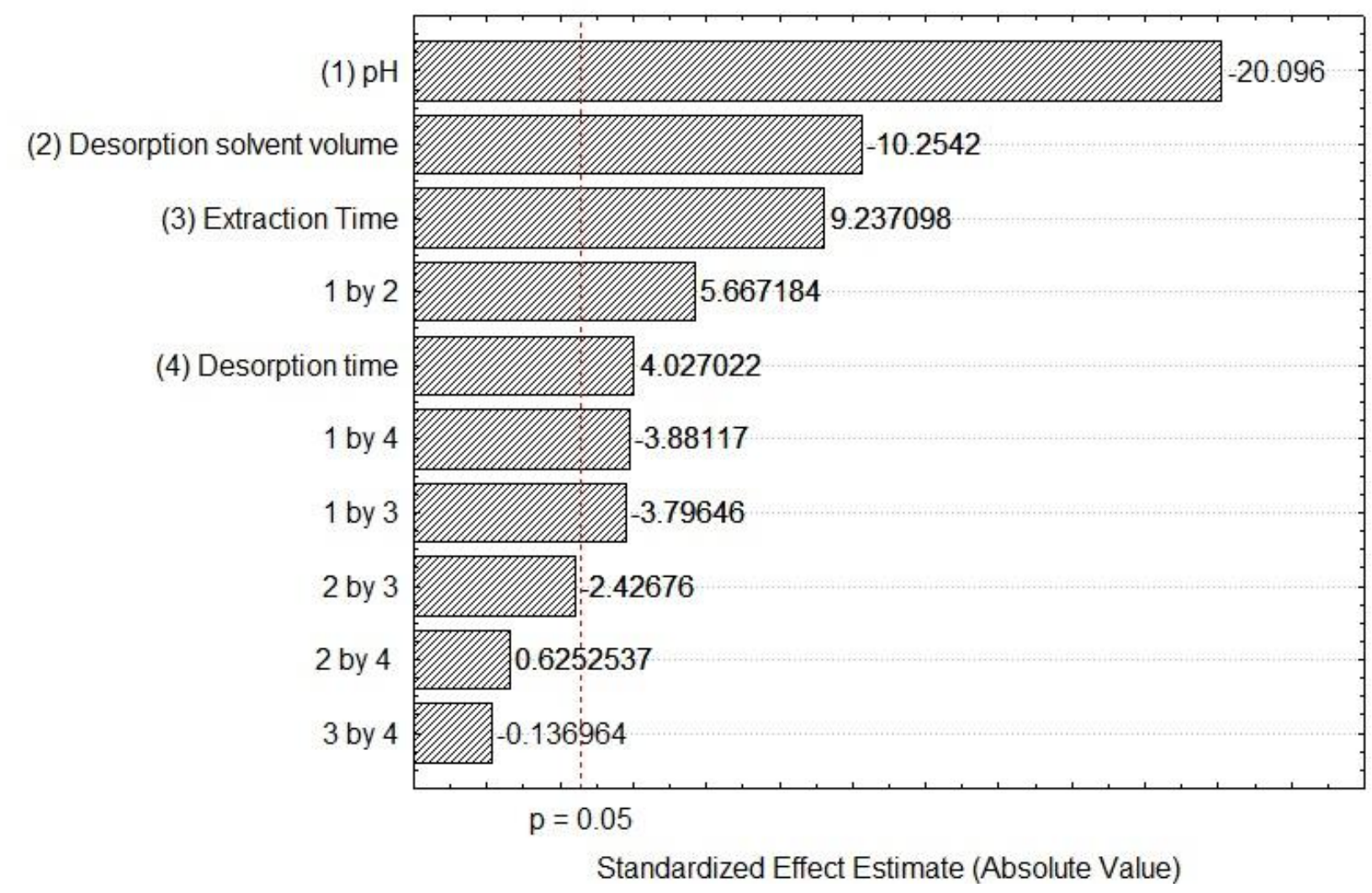


Fig. 3

A.

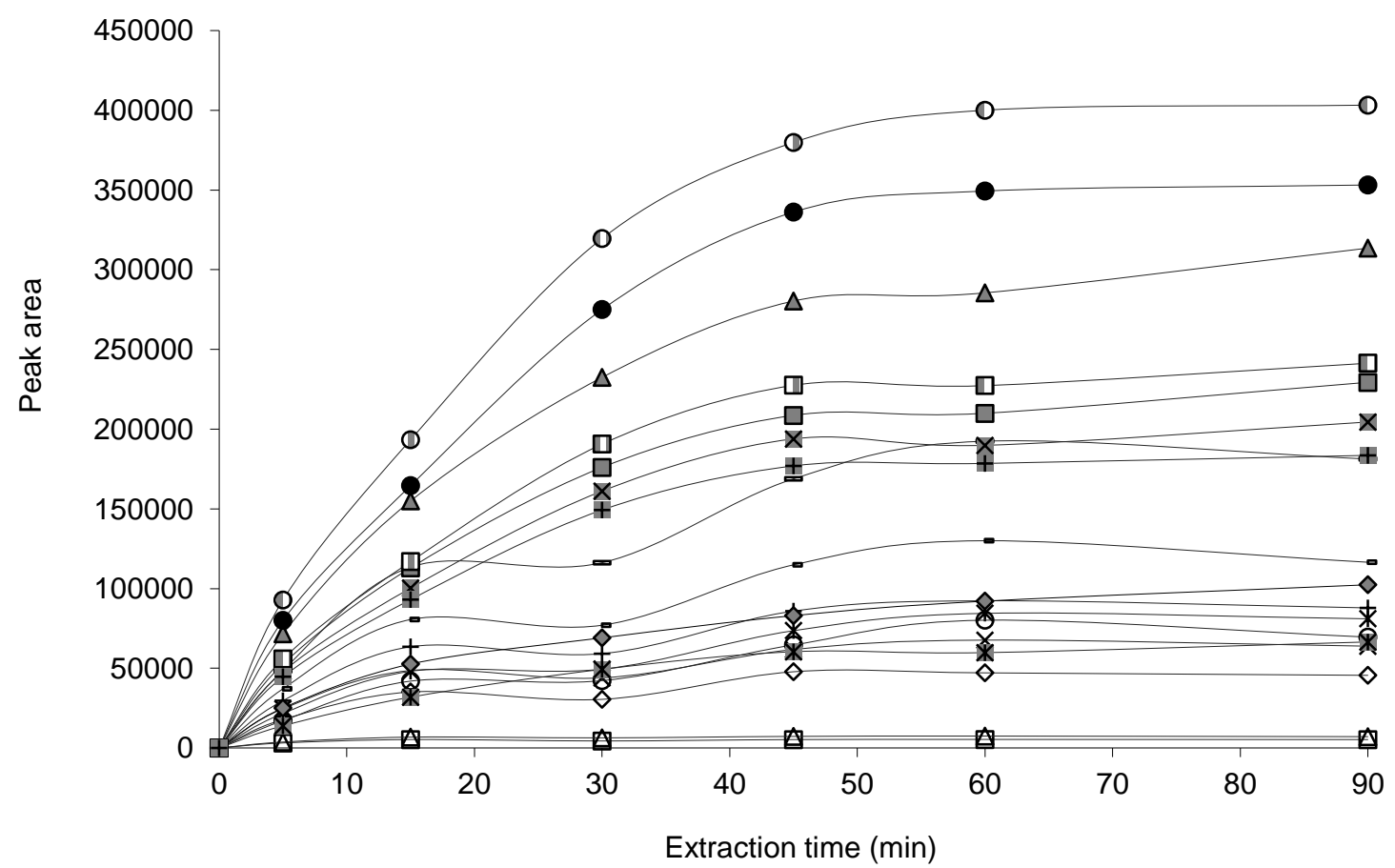

B.

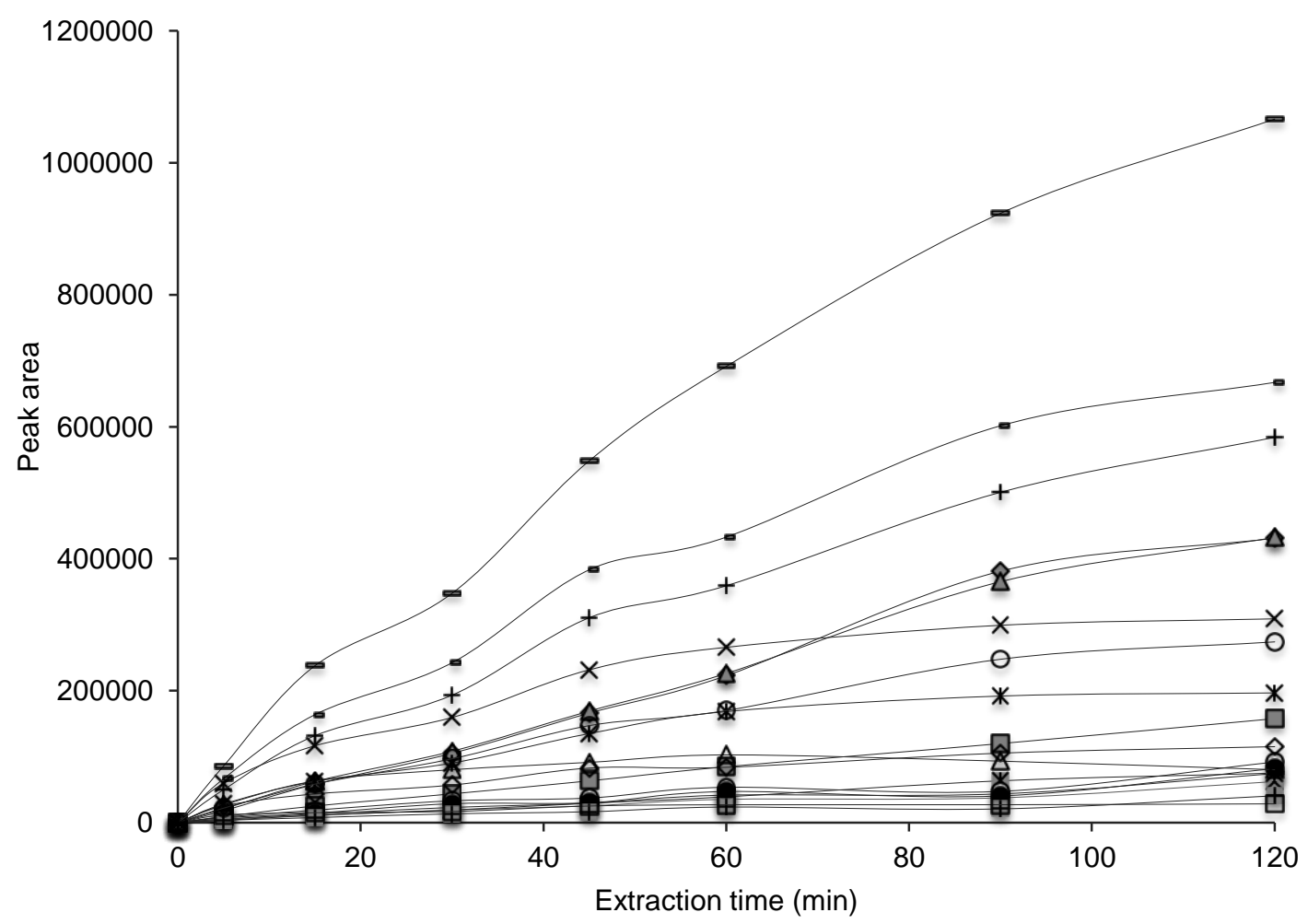


Fig. 4

A.

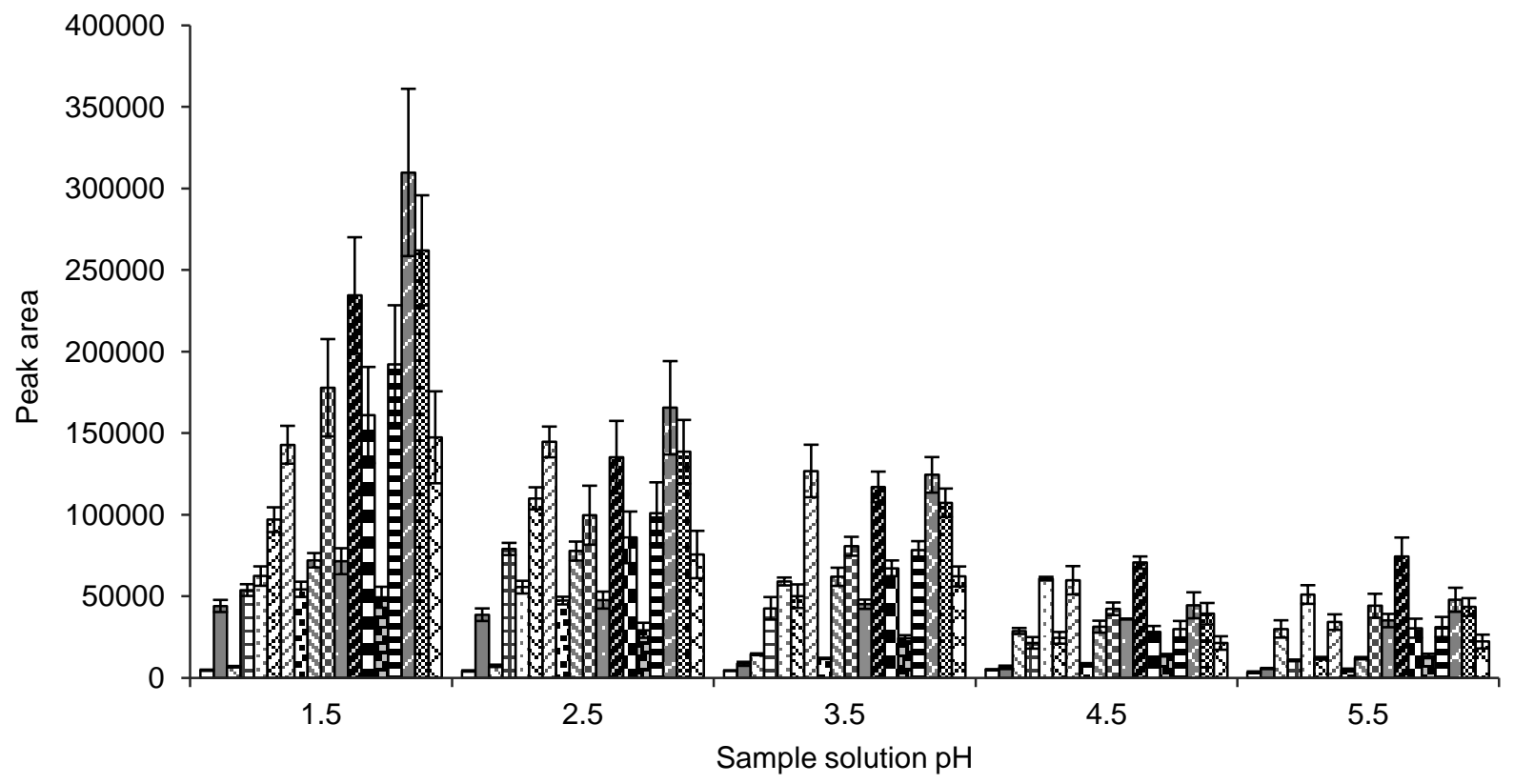

B.

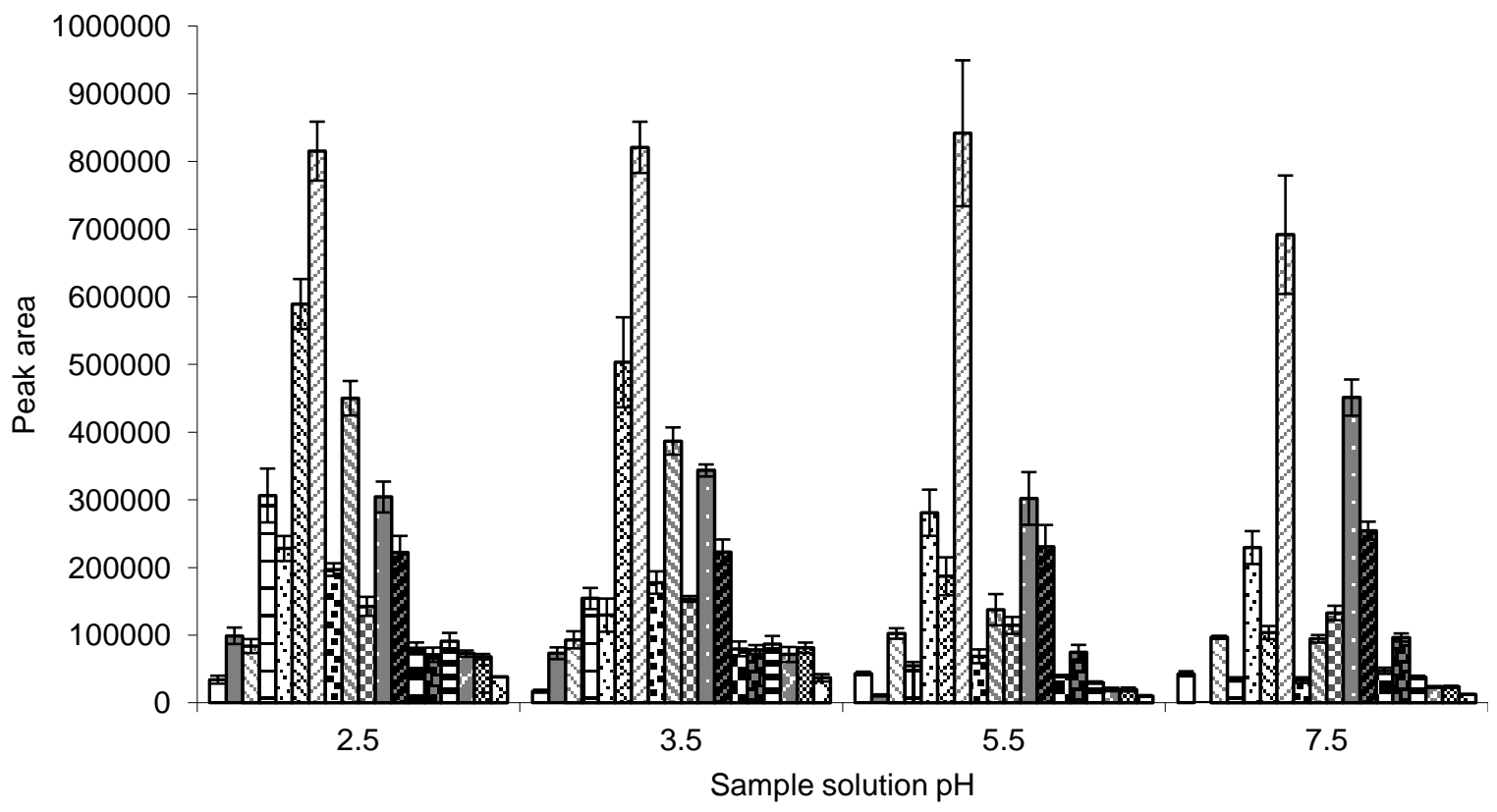


Fig. 5

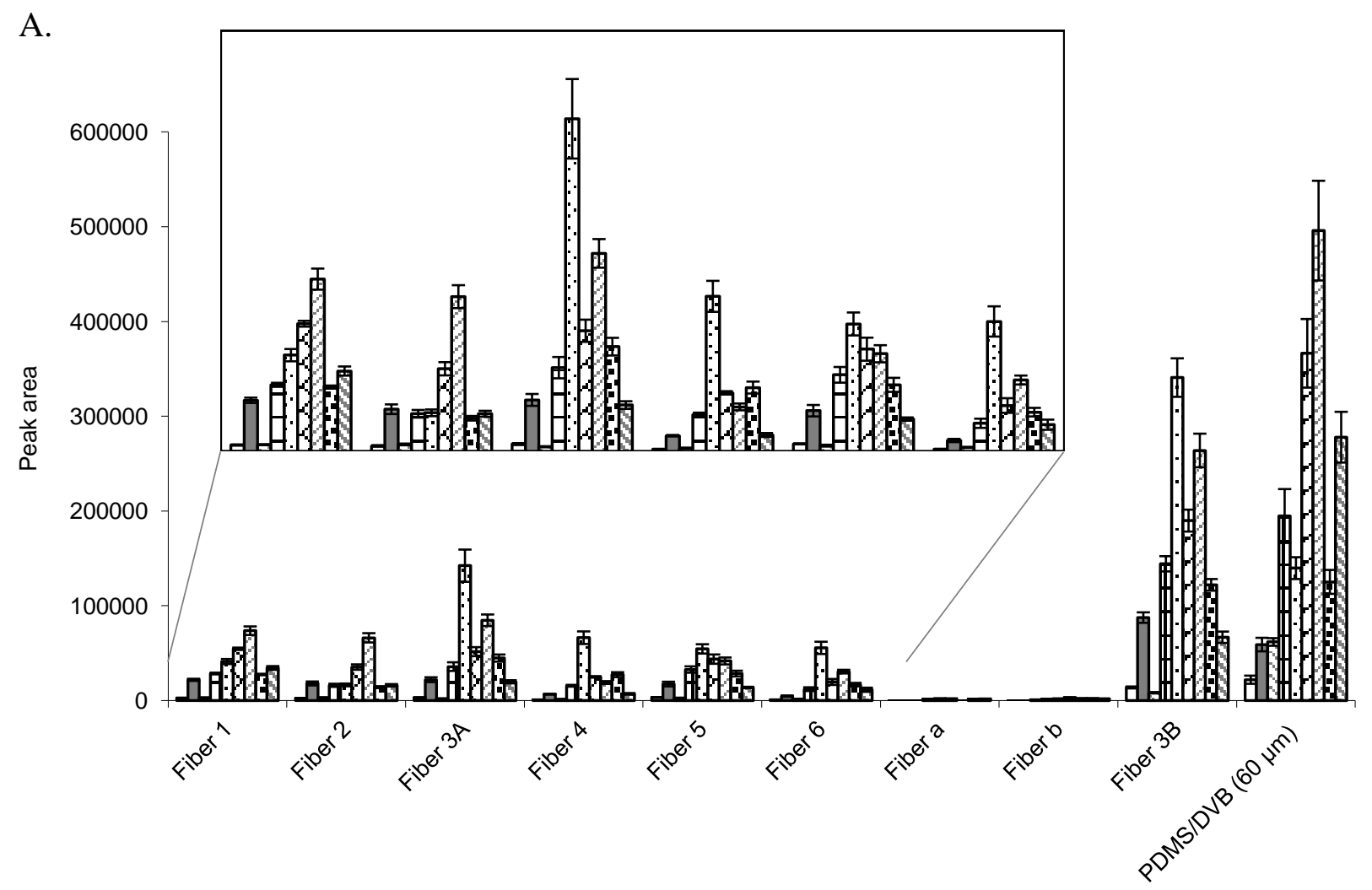

B.

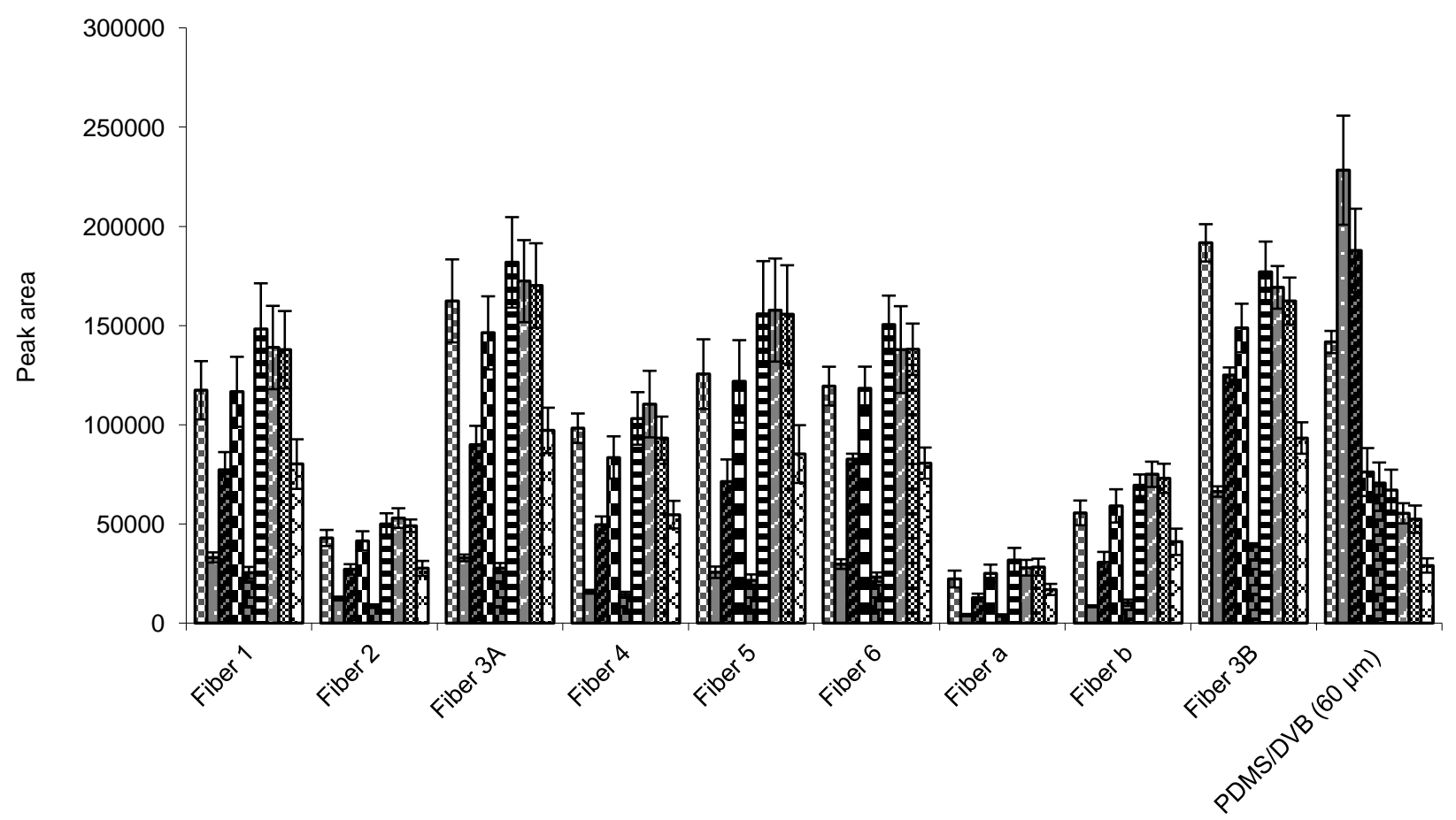


Table 1. Chemical structures and properties of the analytes examined in this study

\begin{tabular}{|c|c|c|c|c|c|}
\hline Name & Structure & Classification & $\log P^{\mathrm{b}}$ & $\begin{array}{l}\log D^{\mathrm{b}} \\
(\mathrm{pH}=2)\end{array}$ & $\mathrm{p} K \mathrm{a}$ \\
\hline Phenacetin & & $\begin{array}{l}\text { Pain- } \\
\text { relieving/ } \\
\text { fever- } \\
\text { reducing drug }\end{array}$ & 1.65 & 1.55 & 5.2 [25] \\
\hline Ketoprofen & & NSAID $^{a}$ & 2.91 & 2.91 & $4.23^{\mathrm{b}}$ \\
\hline $\begin{array}{l}17 \alpha- \\
\text { Ethynylestradiol }\end{array}$ & & $\begin{array}{c}\text { Oral } \\
\text { contraceptive } \\
\text { component }\end{array}$ & $4.11 \quad 4$ & 4.11 & $10.24^{\mathrm{b}}$ \\
\hline $\begin{array}{l}\text { Fenoprofen } \\
\text { calcium }\end{array}$ & & NSAID $^{a}$ & - & - & - \\
\hline $\begin{array}{l}\text { Diclofenac } \\
\text { sodium }\end{array}$ & & NSAID $^{a}$ & $4.06[26$ & 26] & $4.01[26]$ \\
\hline Ibuprofen & & NSAID $^{a}$ & 3.50 & 3.50 & $4.41^{\mathrm{b}}$ \\
\hline $\begin{array}{l}\text { 2,4,6- } \\
\text { Trichlorophenol }\end{array}$ & & $\begin{array}{c}\text { Phenolics; } \\
\text { Organic } \\
\text { pollutant }\end{array}$ & 3.77 & 3.77 & $6.59^{\mathrm{b}}$ \\
\hline 2-Nitrophenol & & $\begin{array}{l}\text { Phenolics; } \\
\text { Organic } \\
\text { pollutant }\end{array}$ & 1.67 & 1.67 & $7.14^{\mathrm{b}}$ \\
\hline
\end{tabular}




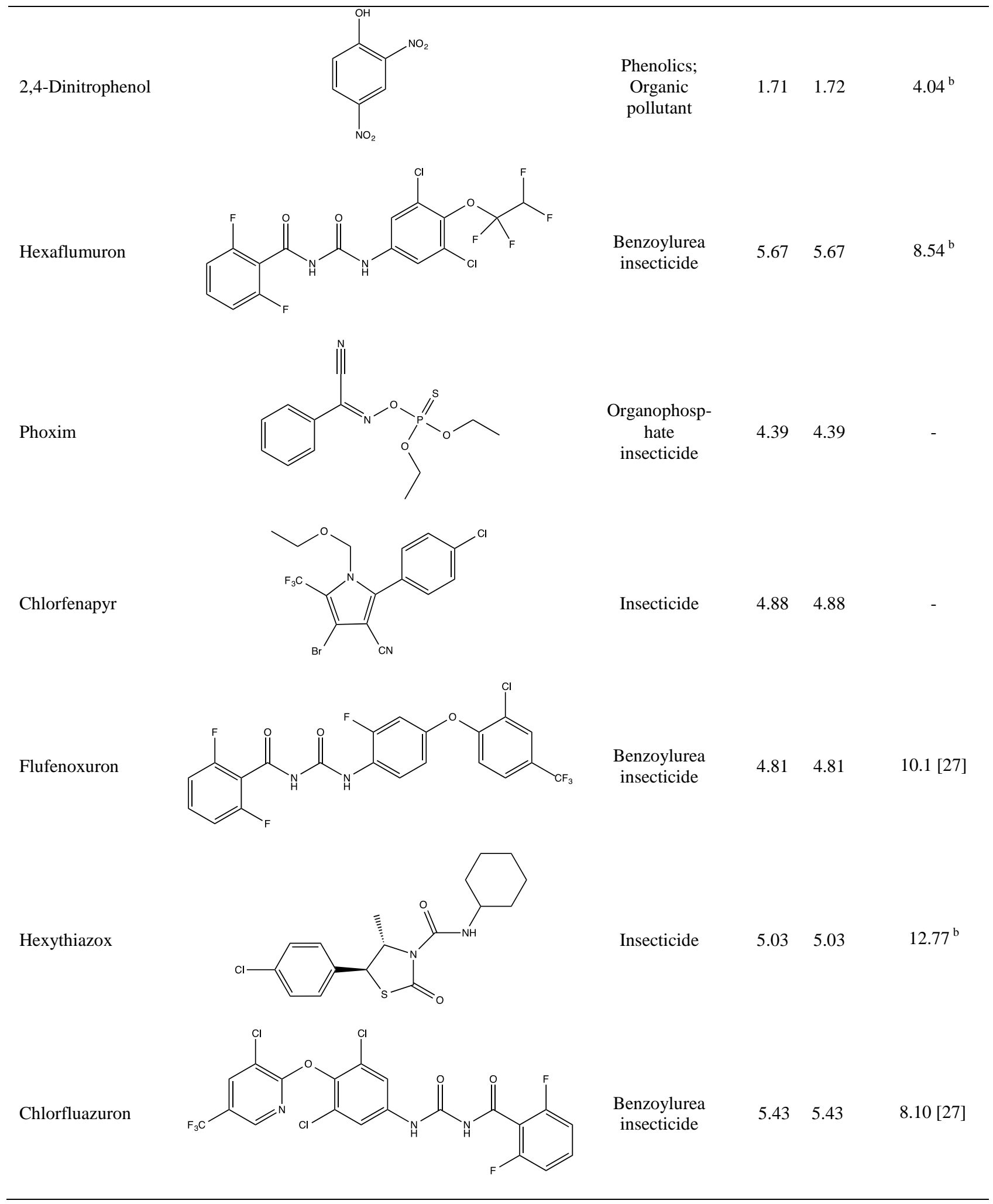




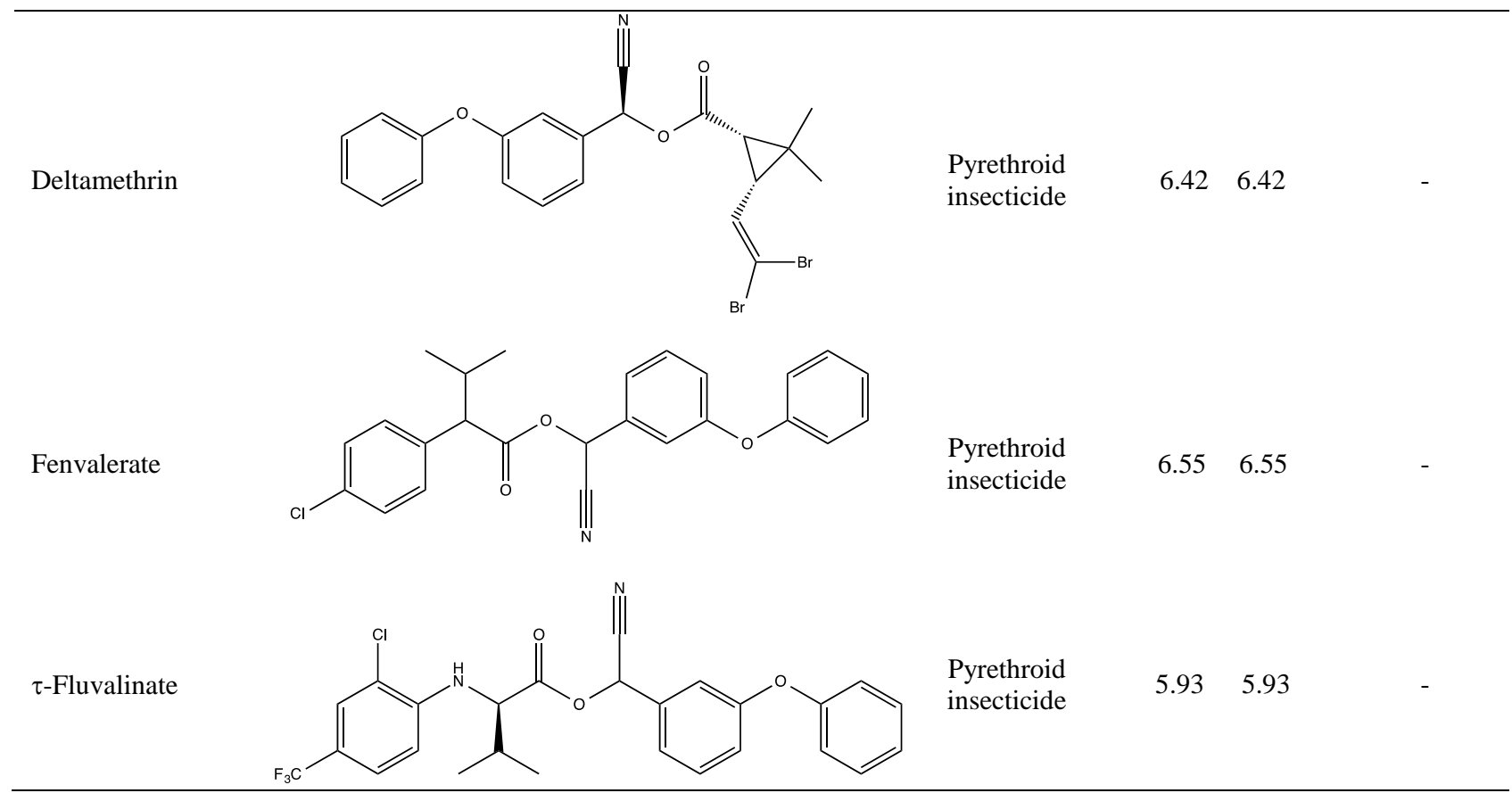

${ }^{a}$ NSAID: Nonsteroidal anti-inflammatory drug

${ }^{\mathrm{b}}$ Obtained from Scifinder and calculated using Advanced Chemistry Development (ACD/Labs) Software V11.02 
Table 2. Structural composition and approximate film thickness of all PIL-based sorbent coatings examined in this study

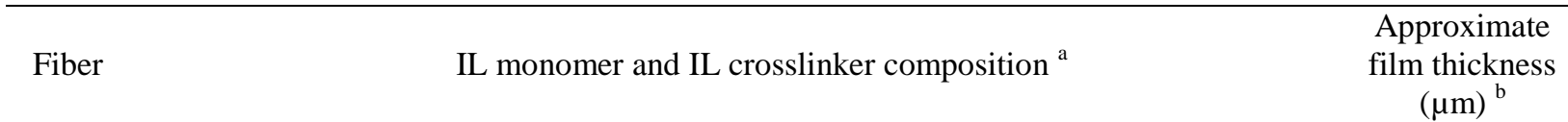

Fiber 1

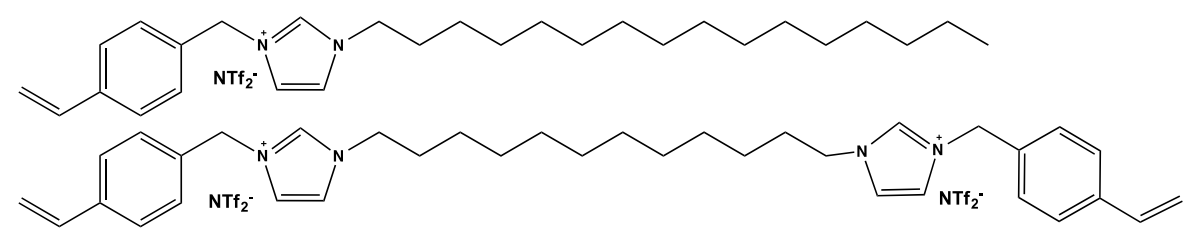

Fiber 2

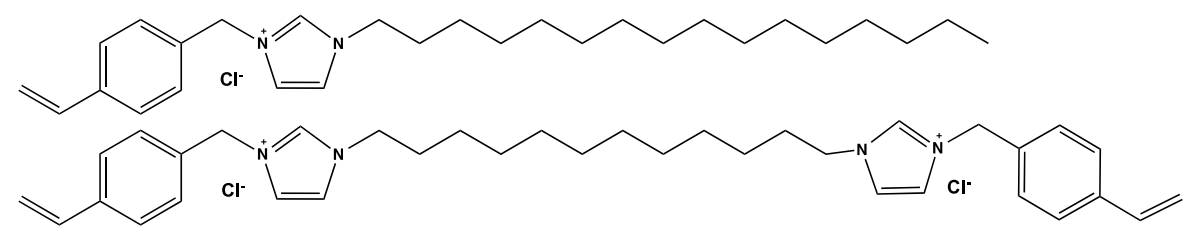

Fiber 3

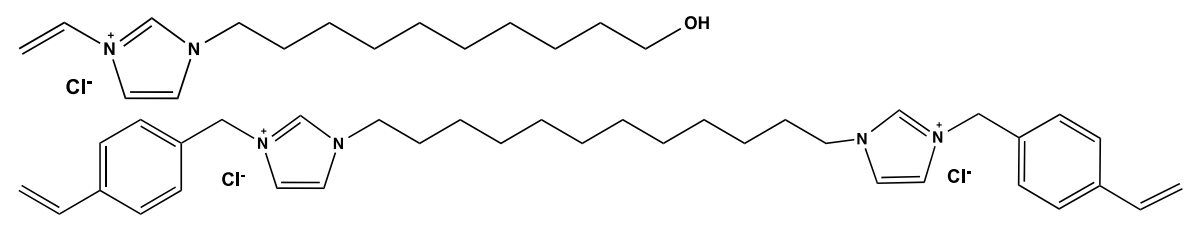

Fiber 4
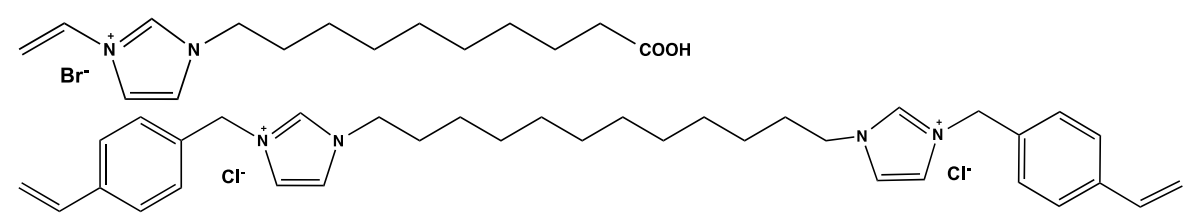

Fiber 5
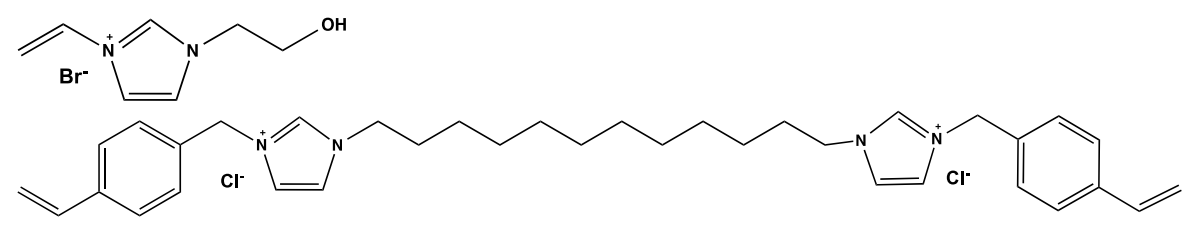

Fiber 6

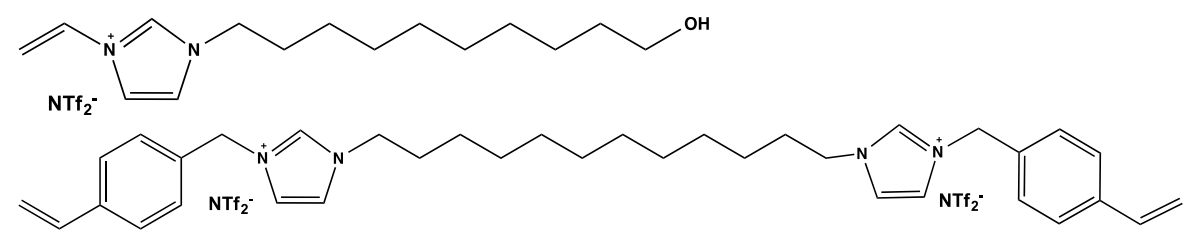

a The IL crosslinker applied within each sorbent coating was $50 \%$ by weight with respect to the IL monomer.

b Approximate film thicknesses of the PIL-based sorbent coatings were obtained by SEM imaging. 
Table 3. Figures of merit for Fiber 3B in the analysis of target analytes

\begin{tabular}{|c|c|c|c|c|c|c|c|}
\hline \multirow{2}{*}{ Analyte } & \multirow{2}{*}{$\begin{array}{c}\text { Linear range } \\
\left(\mu \mathrm{g} \mathrm{L}^{-1}\right)\end{array}$} & \multirow{2}{*}{ Slope \pm error } & \multirow{2}{*}{$\begin{array}{c}\text { LOD } \\
\left(\mu \mathrm{g} \mathrm{L}^{-1}\right)\end{array}$} & \multirow{2}{*}{$\mathrm{R}$} & \multicolumn{3}{|c|}{$\% \operatorname{RSD}(\mathrm{n}=3)$} \\
\hline & & & & & $\operatorname{LOD}^{\mathrm{a}}$ & $1 \mu \mathrm{g} \mathrm{L}^{-1 \mathrm{~b}}$ & $100 \mu \mathrm{g} \mathrm{L}^{-1 \mathrm{c}}$ \\
\hline Phenacetin & $1-500$ & $129 \pm 0.9$ & 0.5 & 0.999 & 11.9 & 3.1 & 1.3 \\
\hline 2,4-Dinitrophenol & $1-500$ & $431 \pm 5.2$ & 0.2 & 0.999 & 17.7 & 15.7 & 2.5 \\
\hline 2-Nitrophenol & $1-500$ & $67 \pm 0.8$ & 0.5 & 0.999 & 8.6 & 17.8 & 0.8 \\
\hline Ketoprofen & $1-500$ & $977 \pm 10.7$ & 0.2 & 0.999 & 13.4 & 6.6 & 3.7 \\
\hline $17 \alpha$-Ethynylestradiol & $1-500$ & $1429 \pm 5.0$ & 0.5 & 0.999 & 8.3 & 13.2 & 1.7 \\
\hline Fenoprofen & $1-500$ & $1178 \pm 5.3$ & 0.5 & 0.999 & 14.0 & 14.5 & 3.0 \\
\hline 2,4,6-Trichlorophenol & $1-500$ & $1224 \pm 9.8$ & 0.5 & 0.999 & 19.0 & 9.2 & 0.3 \\
\hline Diclofenac sodium & $1-500$ & $630 \pm 7.6$ & 0.2 & 0.999 & 19.2 & 17.4 & 4.5 \\
\hline Ibuprofen & $5-500$ & $571 \pm 17.7$ & 2.0 & 0.999 & 13.3 & $\mathrm{~N} / \mathrm{A}^{\mathrm{d}}$ & 3.5 \\
\hline Hexaflumuron & $1-500$ & $1822 \pm 17.8$ & 0.2 & 0.999 & 8.6 & 8.3 & 10.5 \\
\hline Phoxim & $1-500$ & $761 \pm 16.1$ & 0.5 & 0.999 & 14.2 & 13.1 & 3.3 \\
\hline Chlorfenapyr & $1-500$ & $1160 \pm 36.5$ & 0.2 & 0.999 & 4.6 & 6.6 & 7.5 \\
\hline Flufenoxuron & $1-500$ & $2028 \pm 57.2$ & 0.2 & 0.999 & 14.2 & 13.6 & 15.7 \\
\hline Hexythiazox & $1-500$ & $447 \pm 8.9$ & 0.5 & 0.999 & 4.5 & 16.6 & 8.1 \\
\hline Chlorfluazuron & $1-500$ & $2531 \pm 86.7$ & 0.2 & 0.998 & 5.6 & 13.6 & 17.3 \\
\hline Deltamethrin & $1-500$ & $2279 \pm 89.9$ & 0.5 & 0.998 & 7.1 & 7.4 & 16.9 \\
\hline Fenvalerate & $5-500$ & $2461 \pm 112$ & 1.0 & 0.998 & 11.3 & 11.3 & 15.7 \\
\hline$\tau$-Fluvalinate & $1-500$ & $1411 \pm 55.2$ & 0.5 & 0.998 & 10.3 & 18.6 & 18.3 \\
\hline
\end{tabular}

${ }^{\mathrm{a}}$ Precision at LOD; ${ }^{\mathrm{b}}$ Precision at $1 \mu \mathrm{g} \mathrm{L}^{-1} ;{ }^{\mathrm{c}}$ Precision at $100 \mu \mathrm{g} \mathrm{L}^{-1} ;{ }^{\mathrm{d}}$ Not detected 
Table 4. Applications to real water samples using Fiber 3B

\begin{tabular}{lcccc}
\hline \multirow{2}{*}{ Analyte } & \multicolumn{3}{c}{ TRecovery $\pm \mathrm{SD}$} \\
\cline { 2 - 5 } & $1.5 \mu \mathrm{g} \mathrm{L}^{-1 \mathrm{a}}$ & $150 \mu \mathrm{g} \mathrm{L}^{-1 \mathrm{a}}$ & $1.5 \mu \mathrm{g} \mathrm{L}^{-1 \mathrm{a}}$ & $150 \mu \mathrm{g} \mathrm{L}^{-1 \mathrm{a}}$ \\
\hline Phenacetin & $80.2 \pm 3.8$ & $85.8 \pm 5.9$ & $79.8 \pm 10.6$ & $102.1 \pm 12.8$ \\
2,4-Dinitrophenol & $80.5 \pm 3.3$ & $84.2 \pm 7.3$ & $74.0 \pm 9.0$ & $101.1 \pm 12.6$ \\
2-Nitrophenol & $73.8 \pm 2.5$ & $96.0 \pm 7.3$ & $97.4 \pm 14.5$ & $113.6 \pm 5.1$ \\
Ketoprofen & $90.9 \pm 1.3$ & $81.6 \pm 7.2$ & $77.5 \pm 3.2$ & $94.8 \pm 10.1$ \\
$17 \alpha$-Ethynylestradiol & $56.3 \pm 1.0$ & $91.5 \pm 9.8$ & $53.9 \pm 4.7$ & $104.0 \pm 10.1$ \\
Fenoprofen & $86.0 \pm 1.8$ & $82.1 \pm 7.4$ & $81.9 \pm 3.4$ & $93.0 \pm 10.2$ \\
2,4,6-Trichlorophenol & $61.7 \pm 2.4$ & $96.3 \pm 8.5$ & $51.7 \pm 3.3$ & $111.8 \pm 12.3$ \\
Diclofenac sodium & $70.8 \pm 1.5$ & $87.2 \pm 9.4$ & $58.1 \pm 1.3$ & $95.3 \pm 11.4$ \\
Ibuprofen & $94.2 \pm 10.7$ & $77.8 \pm 11.4$ & $106.9 \pm 12.3$ & $89.1 \pm 10.1$ \\
Hexaflumuron & $50.2 \pm 2.1$ & $100.8 \pm 16.5$ & $51.2 \pm 4.0$ & $64.2 \pm 3.9$ \\
Phoxim & $75.0 \pm 1.2$ & $115.9 \pm 14.4$ & $76.9 \pm 4.2$ & $54.0 \pm 9.7$ \\
Chlorfenapyr & $78.1 \pm 1.4$ & $105.8 \pm 15.6$ & $73.7 \pm 5.3$ & $67.6 \pm 3.8$ \\
Flufenoxuron & $80.1 \pm 1.4$ & $91.1 \pm 18.3$ & $84.6 \pm 13.9$ & $52.9 \pm 3.5$ \\
Hexythiazox & $69.2 \pm 7.4$ & $104.5 \pm 11.2$ & $78.7 \pm 1.8$ & $68.7 \pm 1.5$ \\
Chlorfluazuron & $86.1 \pm 2.0$ & $86.9 \pm 17.9$ & $92.3 \pm 14.1$ & $48.8 \pm 2.9$ \\
Deltamethrin & $80.4 \pm 6.1$ & $86.1 \pm 16.6$ & $91.0 \pm 12.6$ & $49.7 \pm 3.4$ \\
Fenvalerate & $103.2 \pm 13.0$ & $87.4 \pm 17.5$ & $116.6 \pm 15.5$ & $52.4 \pm 4.0$ \\
$\tau$-Fluvalinate & $86.6 \pm 4.0$ & $86.4 \pm 18.0$ & $95.0 \pm 19.0$ & $49.1 \pm 4.1$ \\
\hline Spiked concentationyyy & & & & \\
\hline
\end{tabular}

${ }^{\mathrm{a}}$ Spiked concentrations 